This is a pre-print of an article published in Organisms Diversity and Evolution The final authenticated version is available online at https://link.springer.com/article/10.1007\%2Fs13127-020-00447-y

\title{
Insights into mud dragon morphology (Kinorhyncha, Allomalorhagida): myoanatomy and neuroanatomy of Dracoderes abei and Pycnophyes ilyocryptus
}

Maria Herranz ${ }^{1,2^{*}}$, Martin V. Sørensen ${ }^{2}$, Taeseo Park ${ }^{3}$, Brian S. Leander ${ }^{4}$, Katrine Worsaae $^{1}$

${ }^{1}$ Department of Biology, University of Copenhagen, Copenhagen, Denmark; ${ }^{2}$ Natural History Museum of Denmark, University of Copenhagen, Copenhagen, Denmark; ${ }^{3}$ National Institute of Biological Resources, Incheon, South Korea; ${ }^{4}$ Departments of Zoology and Botany, University of British Columbia, Vancouver, Canada.

*Corresponding author e-mail: maria.herranz@bio.ku.dk; mariaherranzm@gmail.com

ORCID-ID: 0000-0002-3020-6072

\begin{abstract}
Comprehensive morphological investigations covering the diversity of metazoan lineages are needed to obtain a complete picture of organ system evolution. Despite the increased amount of studies on lesserknown phyla during the last decades, the gap in knowledge for these lineages is still remarkable. This is the case for kinorhynchs, or mud dragons, where only a few genera, mainly belonging to the major clade Cyclorhagida, have undergone detailed morphological examinations. Here, we explore the neuroanatomy and myoanatomy in the other major clade, Allomalorhagida, through studies of Dracoderes abei and Pycnophyes ilyocryptus by immunochemistry, CLSM and computational 3D reconstruction. The current phylogenetic position of Dracoderes as a sister group to all the remaining allomalorhagids makes it a key taxon for understanding the evolution of organ systems within Kinorhyncha. Clear segmental arrangement of muscles and nerves was found in the trunk of $D$. abei and $P$. ilyocryptus, excluding modifications observed in the posteriormost segments. When comparing current and previous studies of allomalorhagids and cyclorhagids, the nervous system shows a conserved pattern across kinorhynchs, while the musculature shows significant variation among genera. Segmentation in kinorhynchs is restricted to the trunk, including mesoderm (muscles) and ectoderm derivated structures (nerves and glands). The nervous system shows a segmental arrangement in the first eight trunk segments, whereas the last three segments show some deviating arrangements most likely related to a post-hatching development of these segments. The presence of non-segmental trunk muscles is interpreted as adaptations for increased introvert motility and trunk flexibility.
\end{abstract}

\section{Key words}

Segmentation, Nervous system, Musculature, Scalidophora, Ecdysozoa, CLSM. 


\section{Declarations}

\section{Funding}

This project has received funding from the European Union's Horizon 2020 research and innovation programme under the Marie Sklodowska-Curie grant agreement No 797140 to MH. Sampling in South Korea was funded by the Carlsberg Foundation to MVS (CF17-0054). CLSM facilities were supported by the Villum foundation (Grant \# 102544) and the Carlsberg Foundation to KW (CF15-0946). Sampling and SEM in British Columbia was funded by the Hakai Institute and the National Science and Engineering Research Council of Canada (NSERC 2019-03986) to BSL.

\section{Competing interests}

The authors declare that they have no competing interests.

\section{Ethics approval}

Not applicable

\section{Consent for publication}

Not applicable

\section{Consent to participate}

Not applicable

\section{Availability of data and materials}

The data analyzed during the current study is included in this published article. Additional supporting material is available at the Electronic Research Data Archive (ERDA), University of Copenhagen:

https://erda.ku.dk/public/archives/f0787c91e4e82f3bf5f71cd05fab3497/published-archive.html

\section{Code availability}

Not applicable

\section{Author's contributions}

MH, MVS, KW conceived the study. MH, MVS, KW, TP collected and prepared specimens from South Korea and $\mathrm{MH}$ collected and prepared the specimens from Canada. $\mathrm{MH}$ prepared and performed the experiments and imaging at the University of Copenhagen and University of British Columbia. MH prepared all figures and $3 \mathrm{D}$ reconstructions. $\mathrm{MH}, \mathrm{MVS}, \mathrm{KW}, \mathrm{BSL}$ drafted the manuscript. All authors have read and approve the final version of this manuscript.

\section{Acknowledgments}

We are grateful to the Bioimaging facility of University of British Columbia and the staff at Hakai institute for their help during field collections at Quadra Island. Sang-kyu Lee and the Korean National Park Research Institute, Marine Research Center at Yeosu (Korea) are deeply acknowledged for providing laboratory space and support during field collections. 


\section{Introduction}

During the last decade, morphological studies of metazoans using modern techniques have started to cover a broader selection of animal groups, providing new insights into the diversification of organ systems (e.g., Bekkouche et al. 2014; Bekkouche and Worsaae 2016; Gross and Mayer 2015; Kerbl et al. 2015; Martin et al. 2017). Some of these studies have focused on lesser-known taxa, such as the Scalidophora, which includes ecdysozoan groups with a radial head bearing scalids (Kinorhyncha, Loricifera and Priapulida) (Altenburger 2016; Herranz et al. 2013, 2014, 2019a; Martín-Durán et al. 2015; Neves et al. 2013; Rothe and Schmidt-Rhaesa 2010). Despite their similarities in head composition, scalidophorans differ significantly in their external morphology, most dramatically in kinorhynchs, commonly known as mud dragons, which show a segmented body plan. The phylogenomic position of kinorhynchs, always related to non-segmented ecdysozoans (priapulids, loriciferans, nematodes, nematomorphs) and distant to the segmented panarthropods (Giribet and Edgecombe 2017; Laumer et al. 2015), makes the study of their organ systems particularly important for understanding the evolution of segmentation within ecdysozoans.

Kinorhyncha is composed of 31 genera nested into two classes, Cyclorhagida and Allomalorhagida, recovered as monophyletic in recent phylogenetic analyses (Sánchez et al. 2016; Sørensen et al. 2015). Previous detailed morphological studies have largely focused on one allomalorhagid (Setaphyes) and three cyclorhagid genera (Echinoderes, Antygomonas and Zelinkaderes), while information about the internal morphology is still lacking for the majority of the known kinorhynch genera (Kristensen and Higgins 1991; Nebelsick 1992a, 1992b, 1993). Recent morphological studies on kinorhynchs have relied on fluorescent labelling of different components of the nervous system and musculature combined with the use of confocal laser scanning microscopy (CLSM) and three-dimensional rendering. The myoanatomy has been studied in Antygomonas (Müller and Schmidt-Rhaesa 2003), Echinoderes (Herranz et al. 2014), and Setaphyes (Rothe and Schmidt-Rhaesa 2004; Schmidt-Rhaesa and Rothe 2006); neuroanatomical studies have been carried out for the cyclorhagid genera Antygomonas, Zelinkaderes and Echinoderes (Herranz et al. 2013, 2019a) and the allomalorhagid genus Setaphyes (Altenburger 2016) (see Herranz et al. (2019a) for an overview). Despite these recent efforts to understand the internal morphology of kinorhynchs, there are still important gaps of knowledge and an absence of consistent comparable data sets.

Dracoderes was traditionally nested within Cyclorhagida (Sørensen et al. 2012), but recently assigned to Allomalorhagida based on phylogenetic analyses of combined molecular and morphological data placing it as sister group to all remaining allomalorhagids (Dal Zotto et al. 2013; Sørensen et al. 2015; Yamasaki et al. 2013). Morphologically, Dracoderes species presents a mixture of characters from cyclorhagids and allomalorhagids (Sørensen et al. 2012; 2015; Thomsen et al. 2013). Within this phylogenetic framework, Dracoderes constitutes a key taxon to understand the evolution of organ systems within kinorhynchs. Pycnophyes is one of the seven newly defined genera after the revision of the Pycnophyidae (Sánchez et al. 2016). The comprehensive morphological study of a representative of this 
genus complements and provides additional insights into the Pycnophyidae explored previously on only representatives of the genus Setaphyes (Altenburger 2016; Rothe and Schmidt-Rhaesa 2004; SchmidtRhaesa and Rothe 2006).

Our aim is to build a more comprehensive and comparable morphological data set for musculature and nervous systems across Kinorhyncha based on CLSM and three-dimensional reconstruction using standard markers including phalloidin (filamentous actin labeling) for the musculature, and antibodies against acetylated $\alpha$-tubulin, FMRFamide, and serotonin to characterize the nervous system. We test for morphological variation within Allomalorhagida and compare these traits with previous studies of the Cyclorhagida, providing the first comprehensive investigation on the myoanatomy and neuroanatomy of Dracoderes and Pycnophyes, specifically D. abei Higgins and Shirayama, 1990 and P. ilyocryptus (Higgins, 1961) (Higgins 1961; Higgins and Shirayama 1990).

\section{Materials and Methods}

\section{Sampling}

Specimens of Dracoderes abei were collected in May 2018 from muddy sediment at three stations $\left(34^{\circ} 41.483^{\prime} \mathrm{N}, 127^{\circ} 41.283^{\prime} \mathrm{E} ; 4^{\circ} 38.566^{\prime} \mathrm{N}, 127^{\circ} 41.683^{\prime} \mathrm{E}\right.$ and $\left.34^{\circ} 41.308^{\prime} \mathrm{N}, 127^{\circ} 44.080^{\prime} \mathrm{E}\right)$ in Gamak Bay near Yeosu, South Korea. Benthic sediment samples were collected at 5-8 m depth with a Van Venn grab. Specimens of Pycnophyes ilyocryptus were collected in December 2018 from muddy sediment at one station $\left(50^{\circ} 07.365^{\prime} \mathrm{N}, 125^{\circ} 12.888^{\prime} \mathrm{W}\right)$ at $60 \mathrm{~m}$ depth in Hyacinth Bay, Quadra Island, BC, Canada. Sediment was collected with a meiobenthic dredge. Kinorhynchs were extracted from all sediments following the "bubble and blot" method (Higgins and Thiel 1988; Sørensen and Pardos 2008). Live specimens were individually isolated from the sediment, posteriorly identified and fixed with $4 \%$ paraformaldehyde in filtered seawater for $40 \mathrm{~min}$ to $1 \mathrm{~h}$ at room temperature. After fixation, specimens were rinsed several times in phosphate buffered saline (PBS) and stored at $4^{\circ} \mathrm{C}$ in PBS containing $0,05 \%$ of sodium azide $\left(\mathrm{NaN}_{3}\right)$ to prevent microbial growth.

\section{Scanning electron microscopy (SEM)}

Fixed specimens were dehydrated through a graded series of water-ethanol and critical point dried. The dried specimens were mounted in aluminum stubs, sputter coated with a mix of platinum-palladium and imaged with a Hitachi S4700 or a JEOL JSM-6335F field emission scanning electron microscope. Preparation, coating and SEM imaging were carried out at the Natural History Museum of Denmark (NHMD) and the Bioimaging facility at University of British Columbia (UBC). 


\section{Immunohistochemistry (IHC) and confocal laser scanning microscopy (CLSM)}

Twenty-five specimens of Dracoderes abei and 40 Pycnophyes ilyocryptus were selected, stained and imaged. Prior to histochemistry and IHC the cuticle of all specimens was cut using a micro scalpel to facilitate the penetration of the stainings.

For the study of the musculature 12 D. abei and 20 P. ilyocryptus were incubated in PBT (PBS $1 \mathrm{x}+$ $0.25 \%$ bovine serum albumin $+1 \%$ Triton X-100) Alexa Fluor ${ }^{\oplus} 488$ and 633 -labebed phalloidin (INVITROGEN, Carlsbad, USA) (0.33M in 1\% PBT). Incubation was performed at room temperature (RT) for 48 hours ( $D$. abei) or 72 hours ( $P$. ilyocryptus) in glass spot plates.

For the study of the nervous system 13 D. abei and 20 P. ilyocryptus were incubated in PBT for 30 min followed by incubation in blocking solution (PBT $+6 \%$ normal goat serum) overnight. Specimens were then treated with the following primary antibodies: polyclonal rabbit anti-serotonin (Sigma-Aldrich S5545), monoclonal mouse anti-acetylated $\alpha$-tubulin (Sigma-Aldrich T6793) and rabbit anti-FMRFamide (Immunostar 20091) at a concentration of $1: 400$ in blocking solution at $48^{\circ} \mathrm{C}$ for $72 \mathrm{~h}$. Subsequently, specimens were rinsed with multiple exchanges of PBT $1 \%$ and incubated with the corresponding secondary antibodies conjugated with fluorophores: sheep anti-rabbit IgG F(ab')2 fragment labelled with Cy3 (Sigma-Aldrich C2306) and goat anti-mouse labelled with Cy5 (115-175-062, JACKSON IMMUNORESERACH, West Grove, USA) in a final concentration of 1:400. Secondary antibodies were removed with multiple exchanges of PBT, followed by three 15-min exchanges of $1 x$ PBS prior to mounting.

To orientate and guide interpretations of the internal and external anatomy of each species, imaging of the fluorescent cuticle was carried out in combination with musculature and nervous system, acquired as a separate channel with an excitation wavelength of $488 \mathrm{~nm}$.

For CLSM imaging, selected specimens were individually mounted on glass slides in Vectashield ${ }^{\circledR}$ antifade mounting medium containing DAPI (VECTOR LABORATORIES, Burlingame, USA). Specimens were imaged using an OLYMPUS IX 8 inverted microscope in combination with a Fluoview FV-1000 confocal scanning microscope at the Biological Institute, University of Copenhagen. Acquired Z-stacks were compiled with Fiji, version 2.0 (Wayne Rasband, National Institutes of Health). Three-dimensional reconstructions were surface rendered from Z-stacks, segmented and labeled in Amira 6.0 (FEI, SAS). Original CLSM micrographs were edited (e.g., levels, rotation plane, contrast and brightness) with Adobe Photoshop CS6 (Adobe Systems Incorporated, San Jose, CA) and Fiji. Schematics and figure plates were assembled in Adobe Illustrator CS6 (Adobe Systems Incorporated, San Jose, CA).

Positional information used for the identification of external characters, internal anatomy, functional morphology and associated molecular labeling followed the commonly accepted terminology for kinorhynchs (Herranz et al. 2014, 2019a; Sørensen and Pardos 2008). Nervous system terminology follows the neuroanatomical glossary of Richter et al. (2010). 


\section{Results}

\section{External morphology of Dracoderes and Pycnophyes}

Dracoderes and Pycnophyes species share with all other known kinorhynchs a bilaterally symmetric body plan composed of three different regions namely head, neck and trunk where only the trunk is segmented

(Fig. 1). The head, which is radially symmetric and can fully retract into the trunk, is composed of a protrusible mouth cone and an eversible introvert (Fig. 1a, c). The mouth cone bears four rings of oral styles that surround the terminal mouth. The nine outer oral styles are the most prominent whereas the inner oral styles are distributed into three concentric rings of, respectively, five, five and ten styles each. Dracoderes abei has very prominent outer oral styles that alternate in sizes and are articulated, whereas Pycnophyes ilyocryptus has hook-like, equal in length, non-articulated, flexible styles (Fig. 1b, d). The neck is composed of several cuticular placids that alternate with soft and flexible cuticular areas and act as a closing apparatus when the head is retracted into the trunk. In D. abei, the neck closes in a radial manner, while closing is dorsoventral in P. ilyocryptus, also involving the first trunk segment. Number and distribution of neck placids also vary among genera, with nine placids in $D$. abei and six in P. ilyocryptus; in both cases the placid arrangement keeps a bilateral symmetry. The trunk is, as in all adult kinorhynchs, divided into eleven articulated segments, but size and proportions vary, e.g., P. ilyocryptus is three times longer than $D$. abei (ca. $700 \mu \mathrm{m}$ vs. $250 \mu \mathrm{m}$ ). The composition of the first trunk segment differs among genera; Dracoderes has the first trunk segment composed of a cuticular ring and the remaining ten segments divided into a tergal (dorsal) and two sternal (ventral) plates. Pycnophyes instead, has the first trunk segment divided into a tergal plate and three sternal plates (two episternal and one midsternal), whereas the remaining segments are composed of one tergal and one sternal plate. Cuticular trunk specializations differ between D. abei and P. ilyocryptus. D. abei has dorsal spines (alternating into middorsal and paradorsal positions), lateral spines, lateral terminal spines and penile spines (only in males). In turn, P. ilyocryptus lacks any trunk spines (except for the penile spines of males) (Fig. 1a, c). Instead, $P$. ilyocryptus has multiple setae distributed over the trunk, and middorsal specializations (elevations or projections) in some segments. Both D. abei and P. ilyocryptus show cuticular tubes, hairs, glands and sensory spots, with species-specific arrangements. Here we provide the arrangements of cuticular structures in P. ilyocryptus (Table 1); see Sørensen et al. (2012) for a detailed description of cuticular arrangements in $D$. abei. 


\section{Myoanatomy of D. abei}

\section{Introvert}

Myoanatomy of the introvert in $D$. abei includes ten primary spinoscalid muscles, ten sets of W-shaped spinoscalid retractors, ten pairs of long introvert retractors, three introvert circular muscles, and about twelve short introvert retractors (Figs 2, 3). The primary spinoscalid muscles (psm) are short and thick, situated inside the basal sheath of the primary spinoscalids attaching proximally in the dorsal region of the sheath and distally in the joint with the spinoscalid end piece (Figs 2a-b, 3). W-shaped spinoscalid retractors (sr) alternate positions with the primary spinoscalids attaching to the introvert cuticle anteriorly at the level of the second spinoscalid ring and posteriorly at the level of the fourth spinoscalid ring (Figs 2a-c, 3). When the W-shaped muscles (sr) contract and withdraw the head into the trunk, they invert becoming $\mathrm{M}$-shaped (Fig. 2c). The introvert long retractors (ilr) attach to the introvert cuticle at the level of the second row of spinoscalids and extend towards the trunk where they attach in dorsolateral and ventromedial positions at the pachycycli (cuticular thickenings of the anterior segment margins) of segments 3-8 (Figs 2a-b, e, h, 3). The introvert circular muscles are thin (composed of one to three muscle fibers each), and their position changes depending on the level of introvert eversion. When the introvert is everted, the introvert circular muscles are situated underneath the most posterior spinoscalids rings (Figs 2a-b, 3), and below the level of the neck when the introvert is fully retracted. The introvert short retractors (isr) attach anteriorly, adjacent to the introvert circular muscles, and posteriorly to the cuticle of segment 1 in a medial position (Figs 2a-b, $3 \mathrm{a}-\mathrm{c}$ ). These muscles reach their maximum length when the introvert is extended (Fig. 2c).

\section{Mouth cone and gut musculature}

Musculature associated with the mouth cone and gut in $D$. abei includes two rings of concentric circular muscles, five sets of short longitudinal muscles, a pharyngeal bulb, pharynx-associated muscles and intestine-associated muscles. Short longitudinal muscles (osm) are present inside the basal part of each of the five large outer oral styles whereas the remaining four small outer oral styles lack any longitudinal musculature (Figs 2a-b, 3). The circular muscles are situated in the basal part of the mouth cone, one internal and one external $(\mathrm{mcc})$. The external circular muscle is positioned at the base of the outer oral styles whereas the internal circular muscle is situated at the base of the inner oral styles (Figs 2a-b, 3). The pharyngeal bulb $(\mathrm{pb})$ is located posterior to the inner oral styles and is composed of ca. 16 alternating circular and radial muscles. Surrounding the pharyngeal bulb there are four different muscle groups: ten pharynx protractors, at least ten pharynx retractors, ten pharynx longitudinal muscles and a number of delicate gut longitudinal muscles. The pharynx protractors ( $\mathrm{pp}$ ) extend from the posterior end of the pharyngeal bulb inserting, anterior to the introvert, at the level of the first row of spinoscalids (Figs $2 \mathrm{~h}, 3$ ). The pharynx retractors $(\mathrm{pr}$ ) originate near the anterior part of the pharyngeal bulb and extend posteriorly into the trunk toward laterodorsal and ventromedial attachment sites within segments 3-8 (Figs $2 \mathrm{~h}, 3$ ). The 
pharynx longitudinal muscles $(\mathrm{plm})$ attach anteriorly at the base of the mouth cone and posteriorly at the base of the pharyngeal bulb (Figs $2 \mathrm{~h}, 3$ ). The gut longitudinal muscles originate adjacent to the anterior part of the pharyngeal bulb and extend posteriorly, surrounding the esophagus and the intestine (Fig. $2 \mathrm{~h}$ ). Additional circular muscles encircle the longitudinal gut muscles along the intestine forming an orthogonal grid-like pattern. At the hindgut, at least two pairs of short muscles extend from a subdorsal position of segment 10 to tether the intestine dorsally and laterally, identified as hindgut dilator muscles (hd) (Figs $2 \mathrm{j}$, 3). Additionally, there is a dorsal transverse muscle on segment 11 interpreted as a hindgut constrictor (hc) (Figs 2j, 3).

Neck

The neck region contains seven short muscles $(\mathrm{nm})$ - one ventral, four lateral and two dorsal - attaching to the soft cuticle of the interplacid areas (Figs $2 a-b, d, 3 a-c$ ). The muscles are not of equal length, with the ventral muscle twice as long as the dorsal and lateral muscles (Figs 2a-b, 3a-c).

\section{Trunk}

The musculature of the trunk in $D$. abei is compact and consists of several muscle types, some of them expanding along multiple segments, whereas others are segmentally arranged. Segmentally arranged musculature is observed within segments 1-10 and can be grouped into four distinct sets: dorsal, ventral, diagonal and dorsoventral. Dorsal muscle fibers cover the subdorsal region of segments 1-10, originating from the pachycyclus of one segment towards the pachycyclus of the following segment (Figs 2e-f, $3 \mathrm{a}-\mathrm{c}$ ). These fibers are not particularly organized and can be individually discriminated (Fig. 2e-f). Ventral muscle fibers are present in segments 2-11 and extend in the ventromedial and lateroventral areas of each segment originating from the pachycyclus of one segment and attaching to the pachycyclus of the following segment. The ventromedial areas show compact muscle bundles, while in the ventrolateral areas the fibers can be individually discriminated (Figs $2 d, 3 a-c)$. Paired dorsoventral muscles are present in segments 2-11; each muscle is composed of at least three muscle fibers. The dorsoventral muscles attach to the body wall medially in the midventral and laterodorsal/midlateral regions of each segment (Figs 2e-f, 3a-c). Paired diagonal muscles are present midlaterally in segments 2-5 only, composed of 2-3 fibers each that originate from the anterolateral margins of the pachycyclus of one segment, and extending in an oblique way to converge in the pachycyclus of the following segment near the tergosternal junction (Figs 3a-c). Muscles that do not follow a segmental pattern include longitudinal retractors of the introvert (ilr/isr) retractors of the pharynx, and distinct continuous longitudinal muscle fibers in the dorsal and ventral regions (Icf). Some of the dorsal continuous fibers (Icf) originate anteriorly in segment 1 and extend posteriorly to insert at the pachycyclus of segments $4 / 5$ (Figs 3a-c). Other dorsal continuous fibers originate from the pachycyclus of segment 3 and extend towards the pachycyclus of segments $6 / 7$. Individual ventral continuous fibers expand from the pachycyclus of segment 1 towards segment 5, and from the pachycyclus of segment 4 
towards segment 11 in a ventromedial/ventrolateral position (Figs $2 d, 3 a-c)$. Additional strong ventral continuous muscles originate medially on segment 1 in a ventromedial position and attach onto the pachycyclus of segment 6 (Fig. 3a-c).

Additional musculature of the trunk is observed in segments 1 and 11. In segment 1 , a pair of oblique muscles (om) originate from the midlateral region of the neck and extend dorsally to insert onto the pachycyclus of segment 2 in a laterodorsal position (Fig. $2 \mathrm{~g}$ ). On segment 11 the musculature is associated with the lateral terminal spines, tergal plates and penile spines of the males. Each lateral terminal spine has a pair of strong muscles, one levator and one depressor (Figs 2i-j, 3a-c). The terminal spine levator muscles (tsl) are composed of three fibers and originate from the inferior margin of the sternal plates to attach to the base of each of the lateral terminal spines, near to the external margin. The lateral terminal spine depressor muscles (tsd) originate from the pachycyclus of segment 11 and attach to the base of each lateral terminal spine close to the inferior margin (Fig. 2d). A pair of tergal oblique muscles $(\mathrm{tm})$ originates from the pachycyclus of segment 11 in a paradorsal position and attaches close to the external margin of the tergal plates (Figs 2i-j, $3 \mathrm{a}-\mathrm{c}$ ). A pair of thin penile spines muscles (pem) originates in laterodorsal positions of segment 10 and extend posteriorly to attach to at least two of the three penile spines in each side. (Figs 2i, 3 a-c).

\section{Myoanatomy of $\mathrm{P}$. ilyocryptus}

\section{Introvert}

Introvert musculature in $P$. ilyocryptus includes ten $\lambda$-shaped spinoscalid retractor muscles, ten short spinoscalid muscles, ca. five circular muscles, fourteen short retractors and ten pairs of long retractors. Primary spinoscalids lack internal muscles. The $\lambda$-shaped retractor muscles are radially arranged underneath the second row of spinoscalids attaching to the introvert cuticle (Figs $4 a, f, 5$ ). When the introvert is retracted the $\lambda$-shaped muscles invert and become $y$-shaped (Fig 4i). There are several thin introvert circular muscles (icm) distributed in anterior and posterior areas of the introvert. The most anterior circular muscle is located underneath the second row of spinoscalids and the posterior ones (three to five) at the level of scalid rings 4-7 (Figs 4e-f, 5). Alternating with the $\lambda$-shaped muscles and adjacent with the anterior introvert circular muscle are ten short scalid muscles (ism) that attach adjacent to the first circular muscle and distally to the introvert cuticle below the primary spinoscalids (Figs 4e-f, 5). The short retractor muscles (isr) are attached anteriorly, adjacent to the posteriormost circular muscle fibers, and extending towards the pachycyclus of segment 2 (Figs $4 e, i, 5$ ). When the introvert is retracted into the trunk these muscles are inverted (Fig. 4i). The introvert long retractor muscles (ilr) are situated at the level of the second row of spinoscalids below the $\lambda$-shaped muscles and adjacent to the first circular muscle of the introvert (Fig. 5). These retractor muscles extend posteriorly into the trunk toward laterodorsal and ventromedial attachment sites within segments 3-6 (Figs 4a-b, 5c). 
Musculature associated with the mouth cone includes two circular muscles, a pharyngeal bulb, pharynxassociated muscles and intestine-associated muscles. All these structures are movable and their positions change in an anterior-posterior direction accompanying the head. The mouth cone shows two circular concentric muscles (mcc), one external and one internal (Fig. 5a, b, d). The external circular muscle is situated at the base of the outer oral styles which do not show any intrinsic muscles (Fig. $4 \mathrm{~g}$ ). The internal circular muscle is placed at the base of the mouth cone and connects with ten longitudinal muscles (plm) arranged around the pharyngeal bulb. Additionally, there is a ring-like structure composed of several short muscular fibers arranged in a zig-zag manner, located at the base of the mouth cone also connecting with longitudinal muscles that surround the pharyngeal bulb (Figs $4 \mathrm{~g}$, $5 \mathrm{~d}$ ). The pharyngeal bulb is situated below the inner oral styles and is composed of approximately twenty alternating radial and circular muscles. The pharyngeal lumen is triangular in cross section and surrounded by a system of pharynx-associated muscles, including pharynx retractors, pharynx protractors, and gut longitudinal muscles. At least four pharynx protractors are present originating from the posterior part of the pharyngeal bulb and attaching to the introvert cuticle. Approximately ten pharynx retractors originate from the pharyngeal bulb extending posteriorly into the trunk toward laterodorsal and ventromedial attachment sites within segments 4-8 (Figs $4 a, 5 a-c)$. Eight pairs of gut longitudinal muscles arise adjacent to the pharyngeal bulb and extend towards the intestine, bifurcating in the esophagus area. The intestine is enclosed by a grid-like muscular net (gg) composed of ca. sixteen longitudinal gut muscles wrapped by circular muscles. In the hindgut, in segment 10, there is a circular muscle identified as a hindgut constrictor (hc) (Fig. 4d, j).

Neck

The neck region contains sets of longitudinal and transverse muscles associated with the placids. The longitudinal muscles attach anterior to the soft cuticle of the placids and posterior to the pachycyclus of segment 2 in ventromedial and subdorsal positions. These muscles are interpreted to be placid retractors (plr) (Figs 4i, 5a-c). There are two transverse muscles (plt) extending parallel to the anterior edge of the tergal plate of segment 1 and attaching to the soft cuticle of the four dorsal placids (Figs 4h, 5c). Moreover, two pairs of longitudinal muscles attach midlaterally in the soft cuticle of the neck and extend posteriorly towards the pachycyclus of segment 2 and 3. These muscles are interpreted to be neck retractors (nr) (Figs $4 a, i, 5 a)$.

Trunk

The musculature of the trunk in $P$. ilyocryptus consists of several muscle types, some of them expanding along multiple segments whereas other muscles are segmentally arranged. Segmentally arranged musculature is observed within segments 1-10 and can be grouped into three distinct sets: dorsal, ventral 
and dorsoventral. Dorsal muscles are located in subdorsal areas of the tergal plates of segments 1-10 arising from the anteriormost part of one segment and extending towards the pachycyclus of the following segment (Fig. 5a-C). Ventral muscles are present in ventromedial areas of the sternal plates in segments 110 arising from the anterior edge of the segment and extending towards the pachycyclus of the following segment (Figs 4a, 5a-b). On segment 1 and segment 10 the ventral muscles are positioned closer to the paraventral positions compared with the remaining segments (Figs 4a, 5a). Paired dorsoventral muscles are present in segments 1-10, attaching to the cuticle of each segment in ventromedial and laterodorsal areas (Figs $4 a-d, h-j, 5 a-c$ ). Each muscle is composed of three to four fibers. The dorsoventral muscles of segment 1 are considerably thicker than the rest, consisting of at least six muscle fibers, and make up the fundamental part of the closing apparatus (Figs $4 a, h-i, 5$ ). Additionally, a pair of short oblique muscles (om) attach in laterodorsal position on segment 1 extending towards the pachycyclus of segment 2 in ventrolateral position. These muscles are interpreted to assist the closing apparatus by adducting tergal and sternal plates once the head is retracted (Figs 4i, 5a). Trunk musculature that does not follow a segmental pattern include retractors of the introvert (ilr/isr), retractors of the pharynx, neck retractors (nr) and distinct continuous muscle fibers in the subdorsal and ventromedial regions (Icf). Some of the dorsal continuous fibers (Icf) originate in the center of segment 1 and extend posteriorly, attaching at the pachycyclus of segments 6-8 (Figs 4h, 5c). Individual ventral continuous fibers expand from segment 1 towards segments 7-8 in ventromedial position (Figs 4a, i, 5a-b).

Additional muscles of the trunk include a pair of gonopore muscles and a pair of penile spine muscles in males. The gonopore muscles (gpm) are rather short and attaching underneath the cuticle of the gonopores in between segments 10 and 11 in a ventromedial position (Fig. 4j). The penile spine muscles (pem) are composed of several thin fibers that arise medially from segment 10 in a sub-dorsal position and attach to the base of the penile spines midlaterally on segment 11 (Figs 4a, d, 5a-c).

\section{Neuroanatomy of D. abei}

\section{Tubulinergic nervous system}

Acetylated $\alpha$-tubulin-like immunoreactivity ( $\alpha$-tub-LIR) in $D$. abei shows a circumpharyngeal brain with several longitudinal bundles originating radially from the anterior brain region, and extending along the introvert and trunk (Figs 6, 7, 8). The neuropil (np) is composed of a set of condensed neurites forming a ring that narrows on the ventral side (Figs $6 a-b, 8 a-b$ ). Connected to the anterior part of the neuropil, ten radially arranged neurite bundles ( $\operatorname{lnb}$ ) originate in the anterior brain region and extend anteriorly along the introvert, bend 180 degrees towards the body wall and extend posteriorly along the trunk (Fig. 8a-b, d). These neurite bundles have different thicknesses with the ventromedial bundles being much more prominent than the rest (Figs $8 a-b, 7 b-c, 8 a-b)$. At the level of segment 1 to 2 the longitudinal neurite bundles merge two by two forming five longitudinal nerves: one ventromedial, two ventrolateral and two subdorsal (Figs $8 a-b, d-f)$. The paired ventromedial prominent longitudinal bundles converge into a 
midventral nerve cord (vnc) that extends posteriorly throughout the trunk (Figs 6a-b, 7b-c, 8a-b). Within segment 8 the ventral nerve cord splits into two neurite bundles (vncn). From each branch two peripheral neurites originate and innervate segments $9,10,11$, and extend laterally to connect with the subdorsal nerves (Figs 6d, e, 8a-b). From segments 1 to 2, the ventrolateral (vln) and subdorsal nerves (sdn) extend towards trunk segments 8 and 9 respectively (Fig. 8b). The subdorsal nerves, ventrolateral nerves and ventral nerve cord are interconnected through circular transverse neurites (tn) that originate from left and right sides of the ventral nerve cord, medially in segments 1-9 (Fig. 6a-b, 8a-b). The transverse neurites are unpaired in segment 1 and paired in segments 2-9. Additionally, thin diagonal neurites are present ventrally in some trunk segments but without a consistent pattern. Of the five trunk nerves, the ventral nerve cord is the only one that has associated nuclei. These nuclei are arranged along the ventral cord and seem to condense into discrete segmental ganglia in segments 1-8 (Fig. 6g, d). In specimens with a contracted trunk these ganglia are so close to each other that it is difficult to distinguish them individually, giving the appearance of a medullary cord. In segments 8-9, the aggregation of somata in the ventral nerve cord is continuous, extending also into the intersegmental area (Fig. 6d). The architecture of the tubulinergic nervous system of $D$. abei exhibits a segmental organization from segment 1 to 8 .

\section{Innervation of cuticular structures}

Head region: the head region is composed of the introvert and the mouth cone. The scalids are the most prominent cuticular structures of the introvert and the oral styles of the mouth cone (Fig.1a-b). $\alpha$-tub-LIR showed that each of the first row of introvert scalids, named primary spinoscalids, have two neurite bundles (psn) arising from the tip of each spinoscalid and connecting to the anterior part of the neuropil (Fig. 6a-c). Each of the remaining introvert scalids shows single thin spinoscalid neurites (spn) originating from the spinoscalids tip and extending through the anteriormost part of the neuropil (Fig. 6a-c). The mouth cone is composed of four rings of radially arranged oral styles. The outer oral styles (oos) show nine neurites (osn) originating in each style tip, extending posteriorly through the neuropil and bending $180^{\circ}$ to reach the posteriormost part of the brain (Figs 6a-c, 8a-b). All of these oral style neurites (osn) are also connected by a circular neurite (mcnr) situated at the proximal part of the mouth cone (Figs 6b, 8a-b). Neck region: the neck is innervated by a thin $\alpha$-tub-LIR circular neurite (ncn) that might connect with the longitudinal neurite bundles that originate from the neuropil (Fig. 8a-b). The circular neurites of the neck connect ventromedially to the ventral nerve cord through two pairs of oblique short neurites (Fig. 8b). The placids show some $\alpha$-tub-LIR associated with pores situated medially or laterally in each of the placids. These pores seem to be connected through thin longitudinal neurites with the circular neurite of the neck. Trunk region: there are several cuticular structures along $D$. abei trunk with $\alpha$-tub-LIR including: acicular spines, sensory spots, cuticular tubes and penile spines in males. The acicular spines are present in dorsal and lateral positions along the trunk, all of them show neurites (sn) originating at the tip of each spine and connecting with the transverse neurites of the trunk, within the corresponding segment (Figs 6f, 8a-b). The 
lateral terminal spines and penile spines show specific neurites (tsn and pen), respectively, that connect to the posteriormost branches of the ventral nerve cord (Figs 6d-e, 7e, 8b). Cuticular tubes also show neurites (tun) extending towards the transverse neurites of the corresponding segment (Figs 6f, 8b). The sensory spots are oval structures composed of several short papillae and one to two pores from which a cilium originates. Two short neurites (ssn) originate from each sensory spot that correlate with the presence of the external pores and connect to the transverse neurites of the same segment (Figs 6b, 8a-b).

Additionally, non-neuro-specific $\alpha$-tub-LIR was detected in the ciliated ducts of the nephridia (ne) located in subdorsal positions, extending posteriorly from segment 8 to 9 , where they bend 90 degrees laterally and open in sublateral positions (Figs $6 \mathrm{i}, 8 \mathrm{8}$ ). $\alpha$-tub-LIR was also detected in areas surrounding the ovary in $D$. abei females (ovl) originating laterally on segment 5 and extending longitudinally towards a midventral area of segment 9 (Fig. 6h).

\section{Serotonergic nervous system}

Serotonin-like immunoreactivity (5HT-LIR) was studied in three specimens of $D$. abei. All the specimens revealed a common pattern of 5HT-LIR in the neuropil of the brain and the ventral nerve cord (Figs 7a-c, 8c). Within the neuropil four serotonin immunoreactive rings could be observed, two incomplete (inr) and ventrally open and two being completely closed (Figs 7b-c, 8c). The second incomplete ring extends anteriorly to connect with the ventral nerve cord, correlated with the position of the ventral convergent neurites (cne) (Figs 7c, 8c). The complete rings (cnr) are located posterior to the two incomplete rings, also correlated with the position of the neuropil (Figs 7c, 8c). One pair of weakly labeled cell somata were detected in a ventromedial position (vms) in association with the first incomplete ring (Figs $7 \mathrm{~b}-\mathrm{c}, 8 \mathrm{c})$. The ventral nerve cord shows five immunoreactive neurites that extend from segment 2 to 8 , from where only two of the four neurites extend posteriorly towards segment 11 (Figs 7a, a'-c, 8c). These neurites diverge from the ventral midline, each ending in a hook-like shape surrounding the attachment of the dorsoventral muscles of segment 11 (Figs 7a-a', 8c). Cell somata were found associated with the 5HT-LIR ventral nerve cord neurites, at least in segments 5, 7 and 8 . The somata from segments 5 and 8 seem to be unpaired and situated centrally in the ventral nerve cord, whereas the somata from segment 7 are paired and small (Figs $\left.7 a-a^{\prime}, 8 c\right)$.

FMRF-like immunoreactive nervous system

FMRF-like immunoreactivity (FMRF-LIR) was studied in six specimens of $D$. abei. In all the specimens FMRFLIR was consistent in the brain, the ventral nerve cord and transverse neurites of segment 8 (Figs 7d, f-f', 8c). Some specimens showed weak FMRF-LIR in the ventrolateral and dorsolateral cords. Several somata were found associated with the brain and the ventral nerve cord. Within the brain FMRF-LIR was mainly localized in the neuropil and in at least three pairs of somata associated with the anterior brain region (Fig. 7d). FMRF-LIR was also detected in a ring beneath the pharynx. The ventral nerve cord shows intense 
FMRF-LIR along its length until segment 9 (Figs 7d, $f-f^{\prime}, 8 c$ ). Paired somata showing FMRF-LIR are associated with the ventral nerve cord at least on segments 3 and 4, (Figs 7d, 8c). Somata were identified in between segments 8 and 9, where the ventral nerve cord splits (Fig. 7f-f'). Additionally, on segment 8 , two neurites originating from the ventral nerve cord show clear FMRF-LIR, and a pair of somata is found in lateroventral position (Fig. 7f-f'). Non-specific FMRF-LIR was found in lateroventral areas of segment 8 (Fig. 7f-f').

\section{Neuroanatomy of P. ilyocryptus}

\section{Tubulinergic nervous system}

Alpha-tub-LIR in P. ilyocryptus showed a circumpharyngeal brain with ten longitudinal bundles originating from the anterior region of the brain and extending along the introvert and trunk (Figs 9-11). The neuropil $(\mathrm{np})$ is composed of several neurites arranged in a parallel way forming a thick ring that is much narrower ventrally (Figs 9a-b, d, 10 b-c, 11a-b). Ten neurite bundles (Inb) originate in the anterior brain region, next to the anteriormost part of the neuropil, extend anteriorly and bend 180 degrees towards the body wall to extend posteriorly along the trunk (Fig. 11a-b, d). The two ventromedial neurite bundles (cne) are conspicuously thicker than the rest and extend posteriorly along the trunk converging on segment 1 to form the ventral nerve cord (vnc) (Figs 9b, 11b, d). Remaining longitudinal neurite bundles also converge in segment 1 into two ventromedial (vmn) and two subdorsal nerves (sdn) that extend until segment 9 (Figs $9 b, f, 11 a-b, e-f)$. The ventral nerve cord splits into three paired branches in between segment 8 and 9 , each pair extending posterolaterally in segments 9, 10, and 11 (Figs 9e, 10b, 11b). The ventromedial longitudinal nerves (vmn) connect on segment 9 with the lateral branches of the ventral nerve cord, while the subdorsal nerves (sdn) converge middorsally on segment 9 from where several longitudinal neurites arise to innervate segments 10 and 11 dorsally (Figs 9d, e, g, 11a-b). The longitudinal nerves and ventral nerve cord are interconnected through transverse neurite bundles (tn) that originate from left and right sides of the ventral nerve cord in segments 1-9 (Figs 9 b, d, e, 11a-b, f). The transverse neurites are unpaired ventrally (except for segment 1) and paired laterodorsally in segments 2-6 (Figs 9b, d, e, 10b, 11a-b). Segment 1 shows an additional transverse neurite connecting to the ventromedial nerves (Fig. 11b). The ventral nerve cord is associated with nuclei that are aggregated into distinct ganglia on segments 1-8. Most of the cell nuclei of the ventral ganglia are positioned laterally along the cord with longitudinal connectives towards the midline and transverse commissures (Fig. 9c). Somata-free connectives are present in between ganglia coincident with the articulating region between segments (Fig. 9c). Additional longitudinal nerves are not associated with somata (Fig. 9f-g).

\section{Innervation of cuticular structures}

Head region: the most prominent cuticular structures in the head are the scalids of the introvert and the mouth cone styles. All introvert scalids and mouth cone styles show $\alpha$-tub-LIR. From the first row of introvert scalids, the primary spinoscalids (psp), two neurite bundles (psn) extend radially from each scalid 
towards the anterior brain region and connecting to the neuropil (Fig. 9a). Remaining introvert scalids contain single neurites (spn) extending throughout each spinoscalid towards the anteriormost part of the brain and neuropil (Fig. 9a). The mouth cone outer oral styles (oos) show nine radially arranged neurites (osn), along its length, that extend through the neuropil towards the posterior part of the brain (Figs 9a, $11 \mathrm{a}, \mathrm{b})$. All of the oral style neurites (osn) are also connected by a circular neurite (mcnr) situated in the proximal end of the mouth cone (Fig. 11a-b).

Neck region: no prominent $\alpha$-tub-LIR was observed. However, there are some indications of $\alpha$-tub-LIR associated with pores situated medially in each of the placids. These pores seem to be associated with thin longitudinal neurites ( $p / n)$ that connect with the first trunk segment (Fig. 9f).

Trunk region: multiple cuticular structures along the trunk of $P$. ilyocryptus show $\alpha$-tub-LIR. These include sensory spots, middorsal specializations, tergosternal cuticular regions and penile spines. Setae, hairs and sexually dimorphic male tube on segment 2 did not show any associated $\alpha$-tub-LIR. The sensory spots are cuticular oval areas covered with short papillae and one or two pores opening through the cuticle (sometimes with one cilium). Every sensory spot shows two thin neurites (ssn), one of which connects to the transverse neurite of the corresponding segment (Fig. 11a-b). The middorsal specializations are usually longitudinal elevations or projections of the tergal plates; generally, they have a medial pore, and sometimes associated setae and sensory spots. In P. ilyocryptus every middorsal specialization from segments 1-10 send a longitudinal neurite (msn) extending anteriorly along the middorsal line towards the dorsal transverse neurite of the same segment (Figs 9d, $f, 11 a$ ). The end of the neurite seems to correlate with the opening of a cuticular pore. The soft tergosternal cuticular regions (tsj), in the join of the tergal and sternal plates, are typically covered with cuticular hairs and form a small posterior projection. Both the tergosternal region and its projection send longitudinal thin neurites from each segment to join the transverse neurite bundle of the corresponding segment in a midlateral position (tspn) (Figs 9b, d, 11b). Males of $P$. ilyocryptus show two pairs of flexible and tubular penile spines and one fringe-like structure the latter seems to correspond with the position of the gonopores in between segments 10 and 11 . Both the penile spines and the fringed structures send thin individual neurites (pen) towards the ventral nerve cord branches on segment 9 (Fig. 9h, 11b).

Additional non-neuro-specific $\alpha$-tub-LIR was detected in the nephridia (ne) located in subdorsal positions between segments 8 and 9, which might correspond to the staining of the ciliated nephroduct or the flame cells. Male testis ( $t$ ) and female spermatheca (st) also show strong $\alpha$-tub-LIR from the flagella of the sperm cells (Figs 9d, e, 10b).

\section{Serotonergic nervous system}

Serotonin-like immunoreactivity (5HT-LIR) was studied in ten specimens of $P$. ilyocryptus. All the studied specimens showed a common 5HT-LIR present in the brain, mouth cone, ventral nerve cord, ventromedial and subdorsal nerves (Figs 10a, 11c). Additionally, 5HT immunoreactive somata were found associated with 
anterior and posterior areas of the brain and with the ventral nerve cord in several trunk segments (Figs 10c-e, 11c). The 5HT-LIR of the brain is present in the neuropil area as five or six rings. The three to four anterior rings are ventromedially open while the two posterior ones are closed (Figs 10a, c, d, 11c). The most anterior incomplete ring (inr) is connected with a pair of ventromedial somata (vms) (Figs 10a-d, 11c). Remaining incomplete rings extend anteriorly, bend towards the body wall and converge into the ventral nerve cord on segment 1 (Figs 10a-b, 11c). Five to six pairs of 5HT-LIR somata are associated with the incomplete rings, two with the anterior part of the brain and three with the posterior part of the brain (Figs 10b-c, 11c). At least one of the posterior pairs of somata has two neurites connecting with the incomplete rings (Figs $10 \mathrm{a}, \mathrm{c}, 11 \mathrm{c}$ ). The two complete rings (cnr) are located in the posteriormost part of the neuropil and do not connect with any somata. The base of the mouth cone shows two $5 \mathrm{HT}$ immunoreactive rings congruent with the position of the mouth cone nerve ring and associated with at least one pair of somata. The ventral nerve cord shows 5HT-LIR in six to eight neurite strings that extend from the neuropil along the ventral nerve cord reaching segment 9 where just two lateral strings continue into segment 10 diverging from the central midline (Figs 10a-b, 11c). There are paired somata with 5HT-LIR associated with the ventral nerve cord (vncs) in segments 2 and 4-8 (Figs $10 a-b, e, 11 c)$. Segments 2 and 8 only show one pair of somata, segments 5-7 two pairs (segment 5 with an additional midventral somata), and segment 4 has four pairs of associated somata (Figs 10a, e, 11c). 5HT-LIR was also detected in neurites within the ventromedial and subdorsal nerves, however no somata seem to be associated with them. Non-specific 5HT-LIR was found in some of the glands across the trunk.

The attempted studies of the FMRF-like immunoreactive nervous system in P. ilyocryptus were unsuccessful.

\section{Discussion}

\section{Comparative myoanatomy among kinorhynchs}

Multiple studies utilizing a variety of techniques (LM, TEM and CLSM) have provided details on kinorhynch myoanatomy over time, generating a broad amount of information from species belonging to the genera Antygomonas, Echinoderes, Dracoderes, Pycnophyes, Setaphyes and Zelinkaderes (Altenburger 2016; Herranz et al. 2014; Kristensen and Higgins 1991; Müller and Schmidt-Rhaesa 2003; Neuhaus 1994; Nyholm 1976; Rothe and Schmidt-Rhaesa 2004; Schmidt-Rhaesa and Rothe 2006). However, due to the partial nature of most of the descriptions from TEM and LM, comparisons will only refer to the most complete CLSM and TEM studies. Kinorhynchs have a very intricate and complex myoanatomy composed of multiple sets of muscles associated with the head, neck and trunk regions. Most of these muscle groups are consistently found across genera, but their number, fiber composition and precise configuration are highly variable both within and between the two major clades Cyclorhagida and Allomalorhagida. 


\section{Similar vs. variable musculature across Kinorhyncha}

The configuration of trunk musculature seems to be more consistent across kinorhynchs compared with the musculature of the head and neck, which shows more variation. The head is composed of an introvert and a mouth cone. The mouth cone opens into the alimentary canal and bears four rings of styles, where the outer oral styles are the most conspicuous (Neuhaus 2013; Sørensen and Pardos 2008). To date, all studied kinorhynchs show at least two concentric circular muscles, one situated under the outer oral styles that controls their movement, and one at the base of the mouth cone (Altenburger 2016; Herranz et al. 2014; Müller and Schmidt-Rhaesa 2003; Neuhaus 2013). The number and position of the outer oral styles is conserved across kinorhynchs with all the genera showing nine styles. However, their appearance might vary (e.g., fused or partially fused in Campyloderes and Ryuguderes, alternating sizes in Dracoderes and Paracentrophyes, or of nearly same size in Echinoderes), and so does their intrinsic musculature (see Neuhaus (2013) for an overview). Some species lack longitudinal musculature in the outer oral styles such as S. kielensis and P. ilyocryptus (Altenburger 2016), whereas others such as Echinoderes, Antygomonas or Zelinkaderes species have paired longitudinal muscles associated with each of the outer oral styles (Herranz et al. 2014; Müller and Schmidt-Rhaesa 2003; Nebelsick 1993; Neuhaus 1994). Interestingly, D. abei, which has outer oral styles alternating in size, shows longitudinal muscles only inside the five large outer oral styles but not inside the four smaller styles.

The introvert is an eversible structure composed of a variable number of radially arranged rings of scalids, usually between three and seven (Neuhaus 2013; Sørensen and Pardos 2008), controlled by a complex array of musculature. The most prominent scalids are those of the first row, called primary spinoscalids. The number of primary spinoscalids is always constant (ten) but their appearance also varies across the genera (e.g., species of Echinoderes have regular-shaped spinoscalids composed of a short base articulating with a longer distal part versus species of Gracilideres or Franciscideres, that show extremely elongated spinoscalids with bifurcated bases (Dal Zotto et al. 2013; Herranz et al. 2018; Yamasaki 2019). In most of the studied species, no muscles where found inside the primary spinoscalids; however, D. abei shows one thick muscle at the base of every primary spinoscalid, suggesting that they can be moved independently from the other parts of the introvert. Several sets of introvert retractors extend from the introvert to different trunk segments to control the withdrawal of the introvert in all studied kinorhynchs, but their number (between 16-20) varies among species (Herranz et al. 2014; Kristensen and Higgins 1991; Müller and Schmidt-Rhaesa 2003). The introvert retractors are usually associated with shorter muscles that seem to attach in positions that alternate with the primary spinoscalids forming different arrangements (Wshape, $\lambda$-shape or fork-shape) (Altenburger 2016; Herranz et al. 2014; Kristensen and Higgins 1991; Müller and Schmidt-Rhaesa 2003). These muscles assist in the retraction of the scalids and the 180 degrees inversion of the introvert during its withdrawal (Altenburger 2016; Herranz et al. 2014). Additionally, a variable number of shorter introvert retractors are always present in association with at least one circular muscle, and assist in withdrawal and reduction of the diameter of the introvert (Herranz et al. 2014). Some 
kinorhynch species show additional circular muscles, but the position and number of these also varies greatly (e.g., one in Echinoderes species versus five in P. ilyocryptus) (Herranz et al. 2014; this study). All kinorhynchs can fully withdraw their heads into the trunk, and once the head is completely retracted, muscles of the neck and/or anterior trunk segments close (or constrict) the head opening. The closing apparatus for the head opening usually refers to the neck and associated musculature; however, in several genera such as Semnoderes and Pycnophyes, it also involves the first trunk segment (Müller and Schmidt-Rhaesa 2003). Variation in the musculature of the neck and the first trunk segment between species is directly related with the type of closing apparatus, which can be radial (e.g., Echinoderes), lateral (e.g., Semnoderes), dorsoventral (e.g., Pycnophyes) or an intermediate (e.g., Dracoderes radial and dorsoventral, and Antygomonas radial and lateral). The placids of the neck may vary in number and arrangement and can be reduced or even lost in some genera, such as Cateria, Gracilideres and Franciscideres (Herranz et al. 2019b; Neuhaus and Kegel 2015; Yamasaki 2019). The placids are usually associated with muscles that are ring-like in species with a radial closing apparatus, such as Echinoderes (Herranz et al. 2014), or longitudinal in those with a dorsoventral closing apparatus, such as Setaphyes and Pycnophyes species (Altenburger 2016; this study). The configuration of the first trunk segment likewise differs (continuous cuticular ring or divided into differentiated plates), and so do the associated muscles. As an example, $P$. ilyocryptus and $S$. kielensis both have multiple additional muscles on segment 1 assisting the dorsoventral closing apparatus such as placid retractors, transverse muscles and a pair of strong dorsoventral muscles, which all are absent in genera with different closing apparatuses, such as Echinoderes and Antygomonas (Altenburger 2016; Herranz et al. 2014; Müller and Schmidt-Rhaesa 2003). In any given adult kinorhynch, the trunk is composed of eleven articulated segments, most of them exhibiting the same musculature, which includes dorsal, ventral and dorsoventral sets of muscles. The cyclorhagid genera Echinoderes and Antygomonas also show diagonal muscles in most of the trunk segments (Herranz et al. 2014; Müller and Schmidt-Rhaesa 2003). The absence of diagonal muscles in allomalorhagid species has led to the identification of these muscles as a cyclorhagid character (Altenburger 2016; Kristensen and Higgins 1991; Müller and Schmidt-Rhaesa 2003; Neuhaus 2013). However, we found reduced diagonal muscles in some trunk segments of the allomalorhagid $D$. abei, which is not unexpected given the mix of cyclorhagid and allomalorhagid morphological features exhibited in Dracoderes (Sørensen et al. 2015; Thomsen et al. 2013). Additionally, in most of the studied species, continuous longitudinal muscles are found extending across the first six or seven segments, yet absent in segments 7 to 10 (Altenburger 2016; Herranz et al. 2014).

The musculature of the trunk also exhibits certain variation, especially in the first segment (associated with the closing apparatus) and terminal segments. The arrangement of the musculature in the last trunk segments of most kinorhynchs differs from the preceding segments, and between species, due to the presence/absence of posterior structures with associated musculature such as gonopores, penile spines, lateral terminal and midterminal spines (Altenburger 2016; Herranz et al. 2014; Müller and Schmidt- 
Rhaesa 2003; Rothe and Schmidt-Rhaesa 2004). Moreover, most species (including P. ilyocryptus and several Echinoderes species) show absence of either dorsal, ventral or dorsoventral musculature in segment 11 (Altenburger 2016; Herranz et al. 2014; Müller and Schmidt-Rhaesa 2003).

\section{Dracoderes: an allomalorhagid with mixed cyclorhagid/allomalorhagid characters}

Since the description of Dracoderes and its assignment to the Cyclorhagida (Higgins and Shirayama 1990), several studies have pointed out its morphological similarities with species of Pycnophyidae and Neocentrophyidae (formerly known as Homalorhagida) (Sørensen et al. 2012; Thomsen et al. 2013). Later on, phylogenetic analyses also suggested a closer relationship of Dracoderes to Pycnophyidae and Neocentrophyidae rather than to Cyclorhagida (Dal Zotto et al. 2013; Yamasaki et al. 2013). A more recent analysis based on broader taxon sampling, and combined morphological and molecular data further supported this relationship, and Dracoderes was assigned to the new class Allomalorhagida (Sørensen et al. 2015). The present study confirms that the myoanatomy of $D$. abei represents a mix of characters found in the Allomalorhagida and Cyclorhagida, respectively.

Outer oral styles alternating in sizes have been described in members of both Cyclorhagida and Allomalorhagida. However, the differences in the sizes are minimal in cyclorhagids (e.g., in Meristoderes and Tubulideres species, see Herranz and Pardos (2013)), compared with those observed in Neocentrophyidae where the small oral styles are unarticulated and one third of the size of the big ones. The configuration of the outer oral styles in D. abei resembles those in Neocentrophyes, Mixtophyes and Paracentrophyes, and therefore, we would expect the associated muscles to be similar in these genera.

Musculature inside the primary spinoscalids has never been described before for any other kinorhynch besides D. abei; however unpublished data from Antygomonas and Tubulideres (pers. obs. Maria Herranz) confirm their presence in these cyclorhagid genera as well. In addition, Müller and SchmidtRhaesa (2003) showed these muscles in Antygomonas sp. although, interpreting them as oral styles muscles "osm".

The neck in $D$. abei has a reduced number of placids (nine) compared with cyclorhagids (sixteen); however, it has more placids than most allomalorhagids (usually with six or less). The placids in D. abei are controlled by a set of seven short transverse muscles arranged in a polygonal manner. This configuration differs from the muscular ring seen underneath the placids in cyclorhagids (Herranz et al. 2014; Müller and Schmidt-Rhaesa 2003) and the transverse muscles associated with the neck of the studied allomalorhagids from the family Pycnophyidae (Altenburger 2016). In D. abei a pair of oblique muscles, extending from the ventral neck to the dorsal part of segment 1 , uniquely seems to assist the radial muscles of the closing apparatus (this study).

Dracoderes abei shows short diagonal muscles in trunk segments 2 to 4 . So far, diagonal muscles were only described from cyclorhagid genera (Altenburger 2016; Herranz et al. 2014; Müller and SchmidtRhaesa 2003; Neuhaus 2013). The presence of these diagonal muscles have been associated with additional 
flexibility and maneuverability in the anterior region of the trunk, especially concerning lateral and rotational movements (Herranz et al. 2014).

With the recent phylogenetic hypothesis proposing Dracoderes as sister group to all remaining allomalorhagids, the myoanatomical characters of $D$. abei shared with cyclorhagids may represent kinorhynch plesiomorphies (lost in remaining allomalorhagids) rather than cyclorhagid apomorphies, as previously thought.

\section{Comparative neuroanatomy among kinorhynchs}

To date the sources of the neuroanatomical studies in kinorhynchs have been quite diverse (TEM, LM and CLSM) and very often focused on specific regions in TEM studies (Brown 1989; Moritz and Storch 1972; Nebelsick 1992a; Neuhaus 1994), or using specific molecular markers in CLSM studies (Altenburger 2016; Herranz et al. 2013, 2019a) (for overview, see table 1 in Herranz et al. (2019a). Discrepancies in the quantity of longitudinal neurite bundles in the neck and trunk among studies, especially the ultrastructural ones, most likely relate to the challenging interpretation of ultrastructural data (Herranz et al. 2019a). Thus far all studied kinorhynchs, including those of the present study, exhibit a very conserved nervous system composed of: (i) a circumpharyngeal ring-like brain with a somata-neuropil-somata organization; (ii) ten longitudinal neurite bundles arising from the anterior brain region and converging in the first or second trunk segment into 5 nerves ( 2 subdorsal, 2 ventromedial/ventrolateral and a ventral nerve cord); (iii) a ganglionated ventral nerve cord formed anteriorly by the fusion of two longitudinal bundles that bifurcate in the posterior end; (iv) longitudinal nerves encircled in the trunk by at least one pair of transverse neurites per segment originating from the ventral nerve cord; $(v)$ an introvert innervated from the anterior part of the neuropil; and (vi) a mouth cone innervated from the posterior part of the neuropil (Altenburger 2016; Herranz et al. 2019a; Nebelsick 1993). The variability observed among the studied species is related to the innervation of cuticular structures and sensory organs in the head, neck and trunk (Herranz et al. 2019a).

\section{Head}

The introvert of any kinorhynch carries several rows of radially arranged scalids with variable shapes. These scalids function in locomotion, mechanoreception and chemoreception (Brown 1989; Kristensen and Higgins 1991; Moritz and Storch 1972; Nebelsick 1993; Neuhaus 2013). All scalids are connected to the anterior region of the brain by individual neurites that extend along the length of each scalid (Herranz et al. 2019a; Nebelsick 1993; this study). The most prominent scalids in all kinorhynchs are the primary spinoscalids, situated in the first row of the introvert. These are also the ones that show stronger innervation, each of them showing two thick neurite bundles revealed by acetylated $\alpha$-tub-LIR (Herranz et al. 2019a; this study). The variation in innervation of the remaining introvert scalids is associated to their arrangement and number, which differs among species and genera. 
The mouth cone seems to have a very conserved innervation, with nine neurites extending from the outer and inner oral styles towards the posteriormost part of the brain. This pattern is consistently found in the majority of the ultrastructural and immunohistochemical studies done so far (Herranz et al. 2019a; Kristensen and Higgins 1991; Nebelsick 1993).

\section{Neck}

The neck, as discussed for the muscular system, is one of the most variable regions of the kinorhynch anatomy. The differences on the innervation observed in the neck are similar to the myoanatomical variation and correlated with the type of closing apparatus. In radially closing apparatuses, like those of Echinoderes, the neck muscles are innervated by two circular neurites (Herranz et al. 2019a), whereas dorsoventrally closing apparatuses lack circular neurites as seen in P. ilyocryptus (this study). Instead, additional longitudinal neurites extend to the neck muscles (and innervate these) from the first trunk segment. Additionally, in D. abei, a thin ring-like neurite showed $\alpha$-tub-LIR.

The neck is not generally thought to accommodate any sensory structures; however, in Cateria gerlachi Higgins, 1968 sensory spots have been recently reported (Neuhaus and Kegel 2015). The present study shows small neurites expressing $\alpha$-tub-LIR in the same positions as small pores situated medially in the placids of $P$. ilyocryptus, and more distally in D. abei, indicating a sensory function. Future studies should search for these structures in a broader selection of taxa in order to find out whether this character is exclusive for allomalorhagids.

\section{Trunk}

In all kinorhynchs, the nervous system follows a very consistent segmental arrangement in the trunk region. The ventral nerve cord is formed by the fusion of the two most prominent longitudinal bundles that originate from the anterior brain region and extend ventrally along the trunk midline, bifurcating in segment 8 or 9 . In segments 1-8 the ventral nerve cord is composed of ganglia connected by somata-free intersegmental connectives. In $D$. abei, the ganglia of the ventral nerve cord are less conspicuous that in other studied species, because the somata-free connectives are shorter, giving the impression of a medullary cord. This is interpreted as a result of the compacted body plan of Dracoderes species where the segments are broad, very short and highly overlapping. The interganglionic space is shorter compared to those of Echinoderes or Pycnophyes species. P. ilyocryptus shows distinct ganglia, well-spaced apart by somata-free connectives. Importantly, these ganglia seem to be composed of two hemiganglia-like structures that consistently show multiple medial commissures. This arrangement of the ventral nerve cord ganglia in P. ilyocryptus agrees with previous ultrastructural studies which describe "double ganglia" in $S$. kielensis (Kristensen and Higgins 1991). The hemiganglia-like organization with commissures has not previously been visualized with immunohistochemistry in species of Echinoderes or Dracoderes (Herranz et al. 2019a; this study), nor confirmed by ultrastructural studies of Echinoderes species (Nebelsick 1993). 
Most of the variation observed in the nervous system of the trunk is found in the innervation of the multiple sensory spots, spines, and tubes. The transverse neurite numbers vary among species, generally with two per segment although some of the trunk segments might just show a single neurite, such as segment 1 in Echinoderes species or none as in segments 10 and 11 of most studies species (Herranz et al. 2019a). Dracoderes abei also shows some consistent $\alpha$-tub-LIR in the lateroventral area of the trunk in females, most likely associated with the ovaries (this study). Ultrastructural studies from Kristensen and Higgins (1991) described possible innervation of the gonads in Echinoderes aquilonius Higgins and Kristensen, 1988 from ventral ganglia of the last three trunk segments, and gonoducts from dorsolateral ganglia (Kristensen and Higgins 1991). We did not find any evidence of these structures in D. abei, or any connectivity of the labelled structure with the longitudinal nerves or transverse neurite bundles of the trunk. We interpret our findings as non-specific binding to potentially ciliated gonoducts.

\section{Innervation of trunk cuticular characters in kinorhynchs}

Innervation of cuticular characters of the trunk including spines, sensory spots and tubes have been described in detail for Echinoderes species with ultrastructure and immunohistochemistry (Herranz et al. 2019a; Kristensen and Higgins 1991; Nebelsick 1992a; 1993). The number of cuticular structures, location and appearance changes among kinorhynchs species; however, the innervation patterns are similar in all kinorhynchs. All the sensory spots and spines send neurites to the transverse neurites of the corresponding segment (Herranz et al. 2019a; this study). Sensory spots always seem to be associated with two fine neurites independent of genus or species, whereas the spines and tubes usually show either a single neurite or a neurite bundle along all of their lengths (Herranz et al. 2019a; Nebelsick 1992a, 1992b; this study). Interestingly, the big cuticular tubes found in ventromedial position in males of $P$. ilyocryptus do not show any labeling. These tubes have been assumed to be adhesive due to their association with underlying glands, and to intervene in copulation (Kristensen and Higgins 1991; Neuhaus 2013; Zelinka 1928), which might explain the absence of intrinsic innervation. The multiple setae distributed along the surface of the trunk in species of Pycnophyidae have been hypothesized to be either sensorial or secretory (Kristensen and Higgins 1991; Neuhaus 2013). In P. ilyocryptus, the setae lack internal neurites so a sensorial function is unlikely; however, ultrastructural studies are needed to better understand their function. Additional structures found to have a sensorial function in $P$. ilyocryptus are the tergosternal cuticular projections in trunk segments 1-10, which show neurites consistently. Moreover, the middorsal specializations are also found to be sensorial in P. ilyocryptus. These areas can be more or less elevated or elongated along the anterior-posterior axis in different species, and are also used as a diagnostic character in Pycnophyidae. In P. ilyocryptus, every middorsal specialization in segments 1-10, independent of their appearance or association with sensory spot or setae, send neurites towards the transverse neurites of the corresponding segment. These neurites originate medially from a single cuticular pore visible with SEM, and therefore, their function is inferred to be sensory, most likely chemosensory. The middorsal cuticular specializations 
and the tergosternal projections observed in Pycnophyidae have been hypothesized to be homologous to the middorsal and ventrolateral spines found in other kinorhynchs (Neuhaus 1993; Sánchez et al. 2016). However, besides the position we do not find any morphological or ontogenetic evidence that support this hypothesis. Hence, we find it more likely that the middorsal and ventrolateral spines present in most kinorhynch groups were lost before the diversification of Pycnophyidae and Neocentrophyidae.

\section{Serotonin and FMRF-like immunoreactive nervous system in Kinorhynchs}

Immunohistochemical studies tracing neuroactive substances present over a wide taxonomic range, such as FMRFamide and serotonin, have recently been implemented in kinorhynchs. A few studies have explored the serotonin-like immunoreactive patterns in the nervous system of species of Antygomonas, Dracoderes, Echinoderes, Pycnophyes, Setaphyes and Zelinkaderes (Altenburger 2016; Herranz et al. 2013, 2019a; this study). Serotonin-like immunoreactivity shows a conserved distribution in all the studied species, detected within the brain neuropil, the mouth cone nerve ring, ventral nerve cord and sometimes in the ventrolateral nerve cords and transverse nerves (Altenburger 2016; Herranz et al. 2013, 2019a; this study). Differences among genera are related to the number of rings found in the neuropil (four to six), and the number of ventral nerve cord neurites (four to eight). The number and position of the somata connected with the neuropil rings and the ventral nerve cord also varies (Altenburger 2016; Herranz et al. 2013, 2019a; this study). Nonetheless, all the studied species show a conspicuous serotonin-like immunoreactivity (5HT-LIR) in the ventromedial pair of somata in the anterior brain region, which seem to be homologous across Kinorhyncha. Interestingly, from all the studied genera only members of Pycnophyidae (Setaphyes and Pycnophyes) show 5HT-LIR in posterior somata of the brain (Altenburger 2016; this study). However, additional studies of other allomalorhagids are needed to determine if this has any systematic significance. The 5HT-LIR neurites of the ventral nerve cord show variability in the last trunk segments, by either forming a ring in species with a midterminal spine (Antygomonas and Zelinkaderes) or a bifurcation in species lacking it (Dracoderes, Echinoderes, Setaphyes and Pycnophyes), suggesting a correlation of neural organization and species-specific cuticular structures (Herranz et al. 2013, 2019a).

The FMRF-like immunoreactive nervous system in kinorhynchs has so far only been successfully studied in Echinoderes species (Herranz et al. 2019a) and D. abei (this study). Both genera show consistent FMRF-LIR in the brain neuropil and the ventral nerve cord. Multiple somata associated with the anterior brain region appear in Dracoderes and Echinoderes species, however detailed comparisons are challenging due to the weak staining obtained in $D$. abei head. The ventral nerve cord in $D$. abei shows at least five FMRF-LIR somata medially correlated with the position of the ganglion of segment 8 . This is the region where the ventral nerve cord starts splitting into several branches that connect with the posteriormost trunk segments, thus the intense FMRF-LIR detected might be related with the neural control of the functions of segments 9-11. 


\section{Perspectives on segmentation}

\section{Segmented and non-segmented musculature}

All adult kinorhynchs exhibit a combination of continuous (extending across segments) and segmented muscles. Most of the continuous muscles are associated with the movement of the head, pharynx and gut, whereas the segmented muscles are restricted to the trunk. One exception are the trunk longitudinal muscles that extend over several segments in most of the studied kinorhynchs (Altenburger 2016; Herranz et al. 2014; Müller and Schmidt-Rhaesa 2003; Rothe and Schmidt-Rhaesa 2004). The presence of continuous longitudinal muscles in adult Setaphyes kielensis has been interpreted as a reminiscence of the non-segmented musculature present during development in juvenile stages (Rothe and Schmidt-Rhaesa 2004; Schmidt-Rhaesa and Rothe 2006). This has also been used as an argument favoring the hypothesis of the evolution of segmentation in kinorhynchs from an unsegmented ancestor based in ontogeny (Altenburger 2016; Neuhaus 2013; Rothe and Schmidt-Rhaesa 2004; Schmidt-Rhaesa and Rothe 2006). Although we find this plausible, it is important to remark that juvenile stages also show segmentally arranged musculature early in development.

The presence of continuous muscles in the adult trunk helps increasing its flexibility and providing fast contraction of the anterior segments. The presence of long continuous muscles associated with the head and digestive system, which extend and attach into different trunk segments, facilitate the retraction of the head into the trunk, which would not be possible with shorter segmental muscles. The few available developmental studies in kinorhynchs describe juveniles with a fully functional head that can retract into the trunk (Kozloff 1972, 2007). Therefore, the establishment of longitudinal continuous muscles provides control over the head motion early in development.

\section{Segmented and non-segmented nervous system}

The general pattern of the nervous system in all studied kinorhynchs follows a segmental organization with transverse neurites encircling every segment, and distinct ganglia connected by connectives in segments 18 (Altenburger 2016; Herranz et al. 2019a; Kristensen and Higgins 1991; Nebelsick 1993; this study). However, the segmental arrangement of neurites and ganglia is not present in segments 9-11 where the ganglia disappear and the ventral nerve cord splits into several neurites. This transition is consistent across kinorhynchs and is interpreted to be associated with the innervation of the multiple cuticular structures present in the last segments including gonopores, terminal spines and sensory organs (Herranz et al. 2019a). Another interpretation of the organization of the nervous system of segments 9-11 is related to the establishment of the nervous system architecture early in development. Kinorhynchs are direct developers with no more than six juvenile stages. The first juvenile stage has eight or nine segments when it hatches. The remaining two or three segments are added by posterior growth during postembryonic development, by increasing the length of the terminal segment, and subsequently, after the following molt, dividing the 
terminal segment into two (Kozloff 1972; Neuhaus 1993; 2013; Sørensen et al. 2010). Hence, the strictly segmented nervous system was formed during embryonic development, whereas the unsegmented part of the nervous system in the posterior segments is formed during postembryonic development.

\section{Conclusions}

This study provides comprehensive descriptions of the myoanatomy and neuroanatomy in two species of allomalorhagids, representing Dracoderes and Pycnophyes. Results confirm the presence of a conserved nervous system across kinorhynchs agreeing with previous investigations consisting of: (i) circumpharyngeal brain with somata-neuropil- somata construction; (ii) ten longitudinal neurite bundles in the brain converging into five in the trunk; (iii) ganglionated ventral nerve cord; (vi) ventral nerve cord formed by the fusion of two neurite bundles; ( $v$ ) transverse neurites encircling each of the trunk segments; (vi) neurites innervating segmentally arranged sensory structures in the trunk including sensory spots, spines and tubes; (vii) anterior part of the neuropil innervating the introvert and trunk; (viii) posterior part of the neuropil innervating the mouth cone and gut.

Detection of neurites associated with pores in the neck placids of $D$. abei and $P$. ilyocryptus suggest a sensorial function of the neck, at least in allomalorhagids. Additionally, the presence of neurites innervating the middorsal cuticular specializations and tergal-sternal areas in $P$. ilyocryptus revealed their sensorial nature.

Opposite to the nervous system, the myoanatomy is less conserved among genera according to modifications in the outer oral styles of the mouth cone, introvert scalids, closing apparatus (neck and first segment), and presence of movable spines in the trunk. Conserved muscular patterns among the studied species are associated with the digestive system and trunk including dorsoventral, dorsal and ventral muscle sets in most segments.

Segmentation in kinorhynchs is restricted to the trunk and present in several organ systems, including mesoderm (muscles) and ectoderm derived structures (nerves and glands). The nervous system shows a segmental arrangement in the first eight trunk segments, whereas the last three segments show some modifications most likely related to the early establishment of neural architecture in segments 1-8 during embryonic development. Non-segmental muscles present in the trunk region are interpreted as functional adaptations associated with the introvert and digestive system movement and to increase the trunk flexibility. 


\section{References}

Altenburger, A. (2016). The neuromuscular system of Pycnophyes kielensis (Kinorhyncha: Allomalorhagida) investigated by confocal laser scanning microscopy. EvoDevo, 7(1), 25.

Bekkouche, N., \& Worsaae, K. (2016). Neuromuscular study of early branching Diuronotus aspetos (Paucitubulatina) yields insights into the evolution of organs systems in Gastrotricha. Zoological Letters, 2(21), 1-29.

Bekkouche, N., Kristensen, R. M., Hejnol, A., Sørensen, M. V., \& Worsaae, K. (2014). Detailed reconstruction of the musculature in Limnognathia maerski (Micrognathozoa) and comparison with other Gnathifera. Frontiers in Zoology, 11(71), 381-16.

Brown, R. (1989). Morphology and ultrastructure of the sensory appendages of a kinorhynch introvert. Zoologica Scripta, 18(4), 471-482.

Dal Zotto, M., Di Domenico, M., Garraffoni, A., \& Sørensen, M. V. (2013). Franciscideres gen. nov. - a new, highly aberrant kinorhynch genus from Brazil, with an analysis of its phylogenetic position. Systematics and Biodiversity, 11(3), 303-321.

Giribet, G., \& Edgecombe, G. (2017). Current understanding of Ecdysozoa and its internal phylogenetic relationships. Integrative and Comparative Biology, 57(3), 455-466.

Gross, V., \& Mayer, G. (2015). Neural development in the tardigrade Hypsibius dujardini based on antiacetylated $\alpha$-tubulin immunolabeling. EvoDevo, 6(1), 652-15.

Herranz, M., \& Pardos, F. (2013). Fissuroderes sorenseni sp. nov. and Meristoderes boylei sp. nov.: first Atlantic recording of two rare kinorhynch genera, with new identification keys. Zoologischer Anzeiger, 253, 93-111.

Herranz, M., Boyle, M., Pardos, F., \& Neves, R. C. (2014). Comparative myoanatomy of Echinoderes (Kinorhyncha): a comprehensive investigation by CLSM and 3D reconstruction. Frontiers in Zoology, 11(1), 1-26.

Herranz, M., Leander, B. S., Pardos, F., \& Boyle, M. (2019a). Neuroanatomy of mud dragons: a comprehensive view of the nervous system in Echinoderes (Kinorhyncha) by confocal laser scanning microscopy, 19(86), 1-20.

Herranz, M., Di Domenico, M., Sørensen, M. V., \& Leander, B. S. (2019b). The enigmatic kinorhynch Cateria styx Gerlach, 1956 - A sticky son of a beach. Zoologischer Anzeiger, 282, 10-30.

Herranz, M., Pardos, F., \& Boyle, M. (2013). Comparative morphology of serotonergic-like immunoreactive elements in the central nervous system of kinorhynchs (Kinorhyncha, Cyclorhagida). Journal of Morphology, 274(3), 258-274.

Herranz, M., Yangel, E., Leander, B. (2018). Echinoderes hakaiensis sp. nov.: a new mud dragon (Kinorhyncha, Echinoderidae) from the northeastern Pacific Ocean with the redescription of Echinoderes pennaki Higgins, 1960. Marine Biodiversity, 48, 303-325.

Higgins, R. (1961). Three new homalorhage kinorhynchs from the San Juan Archipelago, Washington. Journal of the Elisha Mitchell Scientific Society, 77, 81-88.

Higgins, R. P., \& Shirayama, Y. (1990). Dracoderidae, a new family of the cyclorhagid Kinorhyncha from the Inland Sea of Japan. Zoological Science, 7, 939-946.

Higgins, R., \& Thiel, H. (1988). Kinorhyncha. In: Higgins, R. P. \& Thiel, H. (Eds.), Introduction to the Study of Meiofauna (pp. 328-331). Washington DC: Smithsonian Institution Press.

Kerbl, A., Bekkouche, N., Sterrer, W., \& Worsaae, K. (2015). Detailed reconstruction of the nervous and muscular system of Lobatocerebridae with an evaluation of its annelid affinity. BMC Evolutionary Biology, 15(1), e06614-35.

Kozloff, E. (1972). Some aspects of development in Echinoderes (Kinorhyncha). Transactions of the American Microscopical Society, 91(2), 119-130. 
Kozloff, E. N. (2007). Stages of development, from first cleavage to hatching, of an Echinoderes (Phylum Kinorhyncha: Class Cyclorhagida). Cahiers de biologie marine, 48, 199-206.

Kristensen, R. M., \& Higgins, R. P. (1991). Kinorhyncha. In: F. W. Harrison \& E. E. Ruppert, (Eds.), Microscopic Anatomy of Invertebrates. (Vol. 4, pp. 377-404). New York: Wiley-Liss.

Laumer, C. E., Bekkouche, N., Kerbl, A., Goetz, F., Neves, R. C., Sørensen, M. V., et al. (2015). Spiralian Phylogeny Informs the Evolution of Microscopic Lineages. Current Biology, 1-8.

Martin, C., Gross, V., Pflüger, H. J., Stevenson, P. A., \& Mayer, G. (2017). Assessing segmental versus nonsegmental features in the ventral nervous system of onychophorans (velvet worms), 17(3), 1-22.

Martín-Durán, J. M., Wolff, G. H., Strausfeld, N. J., \& Hejnol, A. (2015). The larval nervous system of the penis worm Priapulus caudatus (Ecdysozoa). Philosophical transactions of the Royal Society of London. Series B, 371(1685), 20150050-11.

Moritz, K., \& Storch, V. (1972). Über den ultrastrukturellen Bau der Skaliden von Trachydemus giganteus (Kinorhyncha). Marine Biology, 16, 81-89.

Müller, M. C., \& Schmidt-Rhaesa, A. (2003). Reconstruction of the muscle system in Antygomonas sp. (Kinorhyncha, Cyclorhagida) by means of phalloidin labeling and cLSM. Journal of Morphology, 256(2), 103-110.

Nebelsick, M. (1992a). Sensory Spots of Echinoderes capitatus (Zelinka, 1928) (Kinorhyncha, Cyclorhagida). Acta Zoologica, 73(3), 185-195.

Nebelsick, M. (1992b). Ultrastructural investigations of three taxonomic characters in the trunk region of Echinoderes capitatus (Kinorhyncha, Cyclorhagida). Zoologica Scripta, 21(4), 335-345.

Nebelsick, M. (1993). Introvert, mouth cone, and nervous system of Echinoderes capitatus (Kinorhyncha, Cyclorhagida) and implications for the phylogenetic relationships of Kinorhyncha. Zoomorphology, 113(4), 211-232.

Neuhaus, B. (1993). Postembryonic development of Pycnophyes kielensis and P. dentatus (Kinorhyncha) from the North Sea. Microfauna Marina, 8, 163-193.

Neuhaus, B. (1994). Ultrastructure of alimentary canal and body cavity, ground pattern, and phylogenetic relationships of the Kinorhyncha. Microfauna Marina, 9, 61-156.

Neuhaus, B. (2013). Kinorhyncha (=Echinodera). In: A. Schmidt-Rhaesa (Ed.), Handbook of Zoology. Gastrotricha, Cycloneuralia and Gnathifera (Vol. 1, pp. 181-348). Berlin: Walter de Gruyter.

Neuhaus, B., \& Kegel, A. (2015). Redescription of Cateria gerlachi (Kinorhyncha, Cyclorhagida) from Sri Lanka and of $C$. styx from Brazil, with notes on $C$. gerlachi from India and C. styx from Chile, and the ground pattern of the genus. Zootaxa, 3965(1), 1-77.

Neves, R. C., Bailly, X., Leasi, F., Reichert, H., Sørensen, M. V., \& Kristensen, R. M. (2013). A complete threedimensional reconstruction of the myoanatomy of Loricifera: comparative morphology of an adult and a Higgins larva stage. Frontiers in Zoology, 10(1), 19-21.

Nyholm, P. (1976). Ultrastructure of the pharyngeal muscles of Homalorhaga Kinorhyncha. Journal of ultrastructure research, 4, 121-130.

Richter, S., Loesel, R., Purschke, G., Schmidt-Rhaesa, A., Scholtz, G., Stach, T., et al. (2010). Invertebrate neurophylogeny: suggested terms and definitions for a neuroanatomical glossary. Frontiers in Zoology, 7(1), 29-49.

Rothe, B., \& Schmidt-Rhaesa, A. (2004). Probable development from continuous to segmental longitudinal musculature in P. kielensis (Kinorhyncha, Homalorhagida). Meiofauna Marina, 13, 21-28.

Rothe, B., \& Schmidt-Rhaesa, A. (2010). Structure of the nervous system in Tubiluchus troglodytes (Priapulida). Invertebrate Biology, 129(1), 39-58.

Sánchez, N., Yamasaki, H., Pardos, F., Sørensen, M. V., \& Martínez, A. (2016). Morphology disentangles the systematics of a ubiquitous but elusive meiofaunal group (Kinorhyncha: Pycnophyidae). Cladistics, 
32(5), 479-505.

Schmidt-Rhaesa, A., \& Rothe, B. (2006). Postembryonic development of dorsoventral and longitudinal musculature in Pycnophyes kielensis (Kinorhyncha, Homalorhagida). Integrative and Comparative Biology, 46(2), 144-150.

Sørensen, M. V., \& Pardos, F. (2008). Kinorhynch systematics and biology an introduction to the study of kinorhynchs, inclusive identification keys to the genera. Meiofauna Marina, 16, 21-73.

Sørensen, M. V., Accogli, G., \& Hansen, J. G. (2010). Postembryonic Development of Antygomonas incomitata (Kinorhyncha: Cyclorhagida). Journal of Morphology, 271(7), 863-882.

Sørensen, M. V., Dal Zotto, M., Rho, H., Herranz, M., Sánchez, N., Pardos, F., \& Yamasaki, H. (2015). Phylogeny of Kinorhyncha Based on Morphology and Two Molecular Loci. PLOS ONE, 10(7), e0133440.

Sørensen, M. V., Herranz, M., Rho, H., Min, W. G., Yamasaki, H., Sánchez, N., \& Pardos, F. (2012). On the genus Dracoderes Higgins \& Shirayama, 1990 (Kinorhyncha: Cyclorhagida) with a redescription of its type species, D. abei, and a description of a new species from Spain. Marine Biology Research, 8(3), 210-232.

Thomsen, V. G., Rho, H., Kim, D., \& Sørensen, M. V. (2013). A new species of Dracoderes (Kinorhyncha: Dracoderidae) from Korea provides further support for a dracoderid-homalorhagid relationship. Zootaxa, 3682(1), 133.

Yamasaki, H. (2019). Gracilideres mawatarii, a new genus and species of Franciscideridae (Allomalorhagida: Kinorhyncha) - A kinorhynch with thin body cuticle, adapted to the interstitial environment. Zoologischer Anzeiger, 282, 176-188.

Yamasaki, H., Hiruta, S. F., \& Kajihara, H. (2013). Molecular phylogeny of kinorhynchs. Molecular Phylogenetics and Evolution, 67(2), 303-310.

Zelinka, K. (1928). Monographie der Echinodera. Leipzig: Verlag Wilhelm Engelmann. 
Table 1. Summary of nature and location of sensory spots, tubes and setae arranged by series in Pycnophyes ilyocryptus. Abbreviations: LD: Laterodorsal; ML: midlateral; PD: paradorsal; SD: subdorsal; VL: ventrolateral; VM: ventromedial; pe, penile spines; se, setae; ss, sensory spot; tu, tube; ( $\left.0^{\urcorner}\right)$, male condition of sexually dimorphic characters. * Marks unpaired setae.

\begin{tabular}{|c|c|c|c|c|c|c|}
\hline $\begin{array}{l}\text { Position } \\
\text { Segment }\end{array}$ & PD & SD & LD & $M L$ & VL & VM \\
\hline 1 & SS & SS, SS & se, ss & & se & \\
\hline 2 & $\mathrm{se}^{*}, \mathrm{ss}$ & SS, SS & se & se & & se, ss, tu( $\left.\sigma^{\top}\right)$ \\
\hline 3 & SS & SS, SS & se, ss & & & se, ss \\
\hline 4 & $\mathrm{se}^{*}, \mathrm{ss}$ & Ss, ss & se, se, ss & se & se & se, ss \\
\hline 5 & ss & SS, SS & se & & se & se, ss \\
\hline 6 & $\mathrm{se}^{*}, \mathrm{ss}$ & SS, ss & se, se & se & & se, ss \\
\hline 7 & SS & SS, ss, ss & se, ss & & & ss \\
\hline 8 & $\mathrm{se}^{*}$ & SS, ss, ss & se, se, ss & se & & SS \\
\hline 9 & & ss, ss & se, se, ss & & & SS \\
\hline 10 & se & ss & SS & se,se & & SS \\
\hline 11 & & SS & & & pe(ठ) & SS \\
\hline
\end{tabular}




\section{Figure captions}

Fig. 1 External anatomy of Dracoderes abei and Pycnophyes ilyocryptus. Scanning electron micrographs, all views with anterior to the top. a. Lateroventral view of $D$. abei, head extended. b. Detail of the mouth cone of $D$. abei in middorsal view showing outer oral styles alternating in size. c. P. ilyocryptus dorsolateral view, head extended. d. Detail of the head of $P$. ilyocryptus in dorsolateral view showing the neck, introvert and mouth cone fully extended. Abbreviations: $h$, head; i, introvert; ios, inner oral styles; mc, mouth cone; $n$, neck; t, trunk; oos, outer oral styles; psp, primary spinoscalids

Fig. 2 Myoanatomy in Dracoderes abei. Confocal 3D reconstruction (a) and z-stack projections (b-j) of specimens labeled with phalloidin. Autofluorescence of the cuticle was kept for guidance in (a-c). Muscles of interest have been colored according to the legend, which applies to all panels. Anterior is up in (a-d, g-j); dorsal is up in (e-f). a-b. Introvert, mouth cone and neck in ventral view. c. Segments 1-4 lateral view, head partially retracted. $\mathbf{d}$. Female, ventral view with the head partially retracted. e-f. Cross sections of different trunk segments in (d), positions indicated by dotted lines. g. Detail of segments 1-2 in lateral view, dorsal is to the left. h. Segments 1-7, ventral view, head partially retracted. i. Segments 10-11 of a male, dorsal view. j. Segments 10-11 of a female, dorsal view. Scale bars: $20 \mu \mathrm{m}$. Abbreviations: glm, gut longitudinal muscle; hc, hindgut constrictor; i, introvert; mc, mouth cone; $\mathrm{n}$, neck; pem, penile spine muscle; tm, tergal muscle; tsd, lateroterminal spine depressor; tsl, lateroterminal spine levator. Numbers refer to segments

Fig. 3 Three-dimensional reconstruction of the myoanatomy in Dracoderes abei. Male with the head extended (a-d). Anterior is up in (a-c), dorsal is up in (d). Autofluorescence of the cuticle was kept for guidance in (a-b). a. Dorsal view. b. Ventral view. c. Lateroventral view showing left side. d. Detail of the head in apical view with introvert and mouth cone extended. Scale bars: $20 \mu \mathrm{m}$. Abbreviations: i, introvert; $\mathrm{mc}$, mouth cone. Numbers refer to segments

Fig. 4 Myoanatomy in Pycnophyes ilyocryptus. Confocal z-stack projections of specimens labeled with phalloidin. Autofluorescence of the cuticle was kept for guidance in (a-d, $f-j)$. Muscles of interest have been colored according to the legend (a), which applies to all panels. Anterior is up in $(a, f-j)$, dorsal is up in (b-e). a. Male, ventral view, head extended. Note the specimen was cut on segment 7 and thus muscles appear damaged. b-d. Cross sections of different trunk segment in (a), positions indicated by dotted lines. e. Apical view of an extended introvert. f-g. Introvert with extended mouth cone in ventral view showing muscles associated with the spinoscalids (f) or associated with the pharynx (g). h. Extended introvert and segments 1-3, dorsal view. i. Segments 1-3, ventral view. j. Segments 8-11, female, ventral view. Double arrowheads indicate the longitudinal muscle fibers extending across segments. Scale bars: $50 \mu \mathrm{m}$. Abbreviations: gg, gut grid; gpm, gonopore muscle; hc, hindgut constrictor; i, introvert; ism, introvert spinoscalid retractor; Icf, 
longitudinal continuous fiber; mc, mouth cone; mcc, mouth cone circular muscle; pem, penile spine muscles; plr, placid retractor. Numbers refer to segments

Fig. 5 Three-dimensional reconstruction of the myoanatomy in Pycnophyes ilyocryptus. Male with the head extended. Anterior is up in (a-c), dorsal is up in (d). Autofluorescence of the cuticle was kept for guidance. Note that segment 7 and 8 were cut and damaged muscles have therefore been omitted. a. Ventral view. b. Lateroventral view showing left side. c. Dorsal view. d. Detail of the head in apical view with introvert and mouth cone extended. Scale bars: $50 \mu \mathrm{m}$. Abbreviations: i, introvert; mc, mouth cone. Numbers refer to segments

Fig. 6 Acetylated $\alpha$-tubulin-LIR in the nervous system of Dracoderes abei. Confocal z-stack projections of specimens co-labeled with $\alpha$-tubulin and DAPI $(a, c, d, f-i)$. Autofluorescence of the cuticle was kept for guidance in $(a, c, d, f, h, i)$. Color legend in (a-b) applies to all panels. Anterior is up in (a-b, d-i), dorsal is up in (c). a-b. Segments 1-4, ventral view, introvert and mouth cone extended. c. Apical view of the extended head, note the mouth cone is protruded. d-e. Segments 5-11 ventral view, female. f. Detail of trunk segments 5 to 8 , ventral view, left side. Note the innervation of the lateroventral acicular spines and tube. g. Detail of the ventral nerve cord showing segmentally arranged ganglia. $\mathbf{h}$. Detail of $\boldsymbol{\alpha}$-tub-LIR associated with the ovary in a female. i. Detail of the $\alpha$-tub-LIR associated with the nephridium, dorsal view, left side. An asterisk (e) marks the position where the ventral nerve cord divides into left and right branches. Scale bars: $20 \mu \mathrm{m}$. Abbreviations: Inb, longitudinal neurite bundle; Its, lateral terminal spine; mc, mouth cone; mcnr, mouth cone nerve ring; ne, nephridium; np, neuropil; oos, outer oral style; osn, outer oral style neurite; ov, ovary; ovl, ovary non-specific labeling; psp, primary spinoscalid; psn, primary spinoscalid neurite bundle; sn, spine neurite; spn, spinoscalid neurite; ssn sensory spot neurite; tn, transverse neurite; tsn, lateroterminal spine neurite; tun, tube neurite; vln, ventrolateral nerve; vnc, ventral nerve cord. Numbers refer to segments

Fig. 7 Acetylated $\alpha$-tubulin-LIR, 5HT-LIR and FMRFamide LIR in the nervous system of Dracoderes abei. Confocal Z-stack projections of specimens co-labeled with 5HT (a-c), FMRFamide (d-f'), $\alpha$-tubulin ( $\left.a^{\prime}, b-c, e\right)$ and DAPI (a, b, e-f). Autofluorescence of the cuticle was kept for guidance in (a, b, e-f) Anterior is up in all panels. a. Segments 1-3 and 5-11 of the same specimen, ventral view, head extended. a'. Detail of the ventral nerve cord marked with a dashed square in (a), left, showing 5HT-LIR; right, 5HT-LIR co-labeled with $\alpha$-tub-LIR. Arrowheads mark the position of somata in the ventral nerve cord. $\mathbf{b}$-c. Segments 1-4 in ventral view, head partially everted. Dashed circles mark the position of somata associated with the neuropil. $\mathbf{d}$. Segments 1-4 in ventral view, heard partially everted. Arrowheads and asterisks mark somata associated with the ventral nerve cord and anterior brain region respectively. e-f. Segments 7-11 in ventral view, male. f'. Detail of FMRF-LIR in the ventral nerve cord in segments 7 and 8, ventral view. Arrowheads mark the 
position of somata at the end of the ventral nerve cord. Note that an additional par of somata with FMRFLIR (asterisks) is present in lateroventral position of segment 8. Scale bars: $20 \mu \mathrm{m}$. Abbreviations: cne, convergent neurites; $c n r$, complete neural rings; inr, incomplete neural ring; $n p$, neuropil; pen, penile spine neurite; t, testis; tn, transverse neurite; vms, ventromedial somata; vnc, ventral nerve cord. Numbers refer to segments

Fig. 8 Schematic representation of acetylated $\alpha$-tubulin-LIR, 5HT-LIR and FMRF-LIR in Dracoderes abei. For clarity, innervation of the introvert scalids has been omitted. Anterior is up in (a-c); dorsal is up in (d-f). 5HT-LIR and FMRF-LIR are overlaid upon a background of $\alpha$-tub-LIR (gray). a-b. Overview of tubulinergic nervous system in (a) dorsal and (b) ventral views. c. Serotoninergic and FMRFamidergic elements of the nervous system, in a ventral view. d-e. Represent cross sections of the positions indicated by an arrowhead in (b). $\mathbf{d}$. Introvert, note the outer ring has 10 radially arranged longitudinal neurite bundles $(x 10)$, the middle ring corresponds with the neuropil, and the inner ring shows 9 oral styles neurites (x9) (see legend). e. Neck, arrowheads mark convergent longitudinal bundles, dark outlines mark the position of the nine cuticular placids. The two ventral bundles with black dots in (c-e) mark the unfused condition of the ventral nerve cord in the head and neck. $f$. Representation of segments 2-7. Abbreviations: cne, convergent neurite; cnr, 5HT-LIR complete nerve ring; inr, 5HT-LIR incomplete ring; Inb, longitudinal neurite bundle; monr, mouth cone nerve ring; ncn, neck circular neurite; ne, nephridium; np, neuropil; osn, outer oral style neurite; pen, penile spine neurite; s, spine; sdn, subdorsal nerve; sn, spine neurite; ssn sensory spot neurite; tn, transverse neurite; tsn, lateroterminal spine neurite; tu, tube; tun, tube neurite; vln, ventrolateral nerve; vms, ventromedial somata; vnc, ventral nerve cord; vncn, ventral nerve cord neurite; vncs, ventral nerve cord somata. Numbers refer to segments

Fig. 9 Acetylated $\alpha$-tubulin-LIR in the nervous system of Pycnophyes ilyocryptus. Confocal Z-stack projections of specimens co-labeled with $\alpha$-tubulin and DAPI (a, c, f-g). Autofluorescence of the cuticle was kept for guidance in all panels. Color legend in (a) applies to all panels. Anterior is up in all panels. a. Head with introvert and mouth cone fully protruded, lateral view. Note that the brain is inverted due to the overextension of the mouth cone. b. Segments 1-5 in ventral view, head completely retracted. c. Detail the ventral nerve cord showing ganglia in trunk segments 6-7. Arrowheads mark the commissures. $\mathbf{d}$. Lateral view of a full specimen with the head retracted. Note the non-neural labeling of the sperm cells in the testis. e. Segments 7-11 ventral view, female. Note the non-neural staining of the sperm in the spermatheca. Asterisk marks the location where the ventral nerve cord divides into left and right branches. f. Segments 1 to 3, dorsal view, head partially extended. g. Segments 8-11 in dorsal view. Note the nonneural labeling of the nephridia. $\mathbf{h}$. Detail of segments 10-11 showing the innervation of the penile spines in a male, ventral view. Scale bars: $50 \mu \mathrm{m}$. Abbreviations: b, brain; cne, convergent neurites; i, introvert; Inb, longitudinal neurite bundle; mc, mouth cone; mcnr, mouth cone nerve ring; msn, middorsal specialization 
neurite; ne, nephridium; np, neuropil; osn, outer oral style neurite; pen, penile spine neurite; pln, placid neurite; psn, primary spinoscalid neurite; sdn, subdorsal nerve; spn, spinoscalid neurite; ssn sensory spot neurite; st, spermatheca; tn, transverse neurite; tspn, tergosternal projection neurite; vnc, ventral nerve cord; vncn, ventral nerve cord neurite; vmn, ventromedial nerve. Numbers refer to segments

Fig. 10 Acetylated $\alpha$-tubulin-LIR and 5HT-LIR in the nervous system of Pycnophyes ilyocryptus. Confocal Zstack projections of specimens co-labeled with $5 \mathrm{HT}(\mathrm{a}-\mathrm{e})$ and $\alpha$-tubulin (b-e). Autofluorescence of the cuticle was kept for guidance in (b, d, e). Anterior is up in all panels. a-b. Ventral view of male with head fully retracted. Arrowheads mark somata associated with the ventral nerve cord. c. Detail of the neuropil from (b) showing the position of the somata associated with the neuropil. Asterisks mark the position of the somata with two neurites. $\mathbf{d}$. Detail of the neuropil from (b) in lateral view. Dashed circles mark the position of the somata. e. Segments 4-6 in ventral view, male. Dashed circles mark the position of the somata associated with the ventral nerve cord. Note the non-neural labeling of the sperm cells from the testis. Scale bars: $50 \mu \mathrm{m}$. Abbreviations: cne, convergent neurites; inr, incomplete neural ring; mcnr, mouth cone nerve ring; $n p$, neuropil; sdn, subdorsal nerve; spn, spinoscalid neurite; $t$, testis; vms, ventromedial somata; vmn, ventromedial nerve; vnc, ventral nerve cord. Numbers refer to segments

Fig. 11 Schematic representation of acetylated $\alpha$-tubulin-LIR and 5HT-LIR in Pycnophyes ilyocryptus. For clarity innervation of the introvert scalids has been omitted. Anterior is up in (a-c); dorsal is up in (d-f). 5HTLIR is overlaid upon a background of $\alpha$-tub-LIR (gray). a-b. Overview of tubulinergic nervous system in (a) dorsal and (b) ventral views. c. Serotoninergic elements of the nervous system, in a ventral view. d-e. Represent cross sections of the positions indicated by an arrowhead in (b). $\mathbf{d}$. Introvert, note the outer ring has 10 radially arranged longitudinal neurite bundles $(x 10)$, the middle ring corresponds with the neuropil, and the inner ring shows 9 oral styles neurites (x9) (see legend). e. Neck, arrowheads mark convergent longitudinal bundles, dark outlines mark the position of the nine cuticular placids and first segment. The two ventral bundles with black dots in (d-e) mark the unfused condition of the ventral nerve cord in the head and neck. $\mathbf{f}$. Representation of segments 2-8. Abbreviations: asb, anterior somata of the brain; cne, convergent neurite; $\mathrm{cnr}$, complete nerve ring; inr, incomplete nerve ring; Inb, longitudinal neurite bundle; mcnr, mouth cone nerve ring; msn, middorsal specialization neurite; ne, nephridium; np, neuropil; osn, outer oral style neurite; pen, penile spine neurite; psb, posterior somata of the brain; sdn, subdorsal nerve; ssn sensory spot neurite; th, transverse neurite; tspn tergosternal projection neurite; vmn, ventromedial nerve; vnc, ventral nerve cord; vncn, ventral nerve cord neurite; vncs, ventral nerve cord somata. Numbers refer to segments 


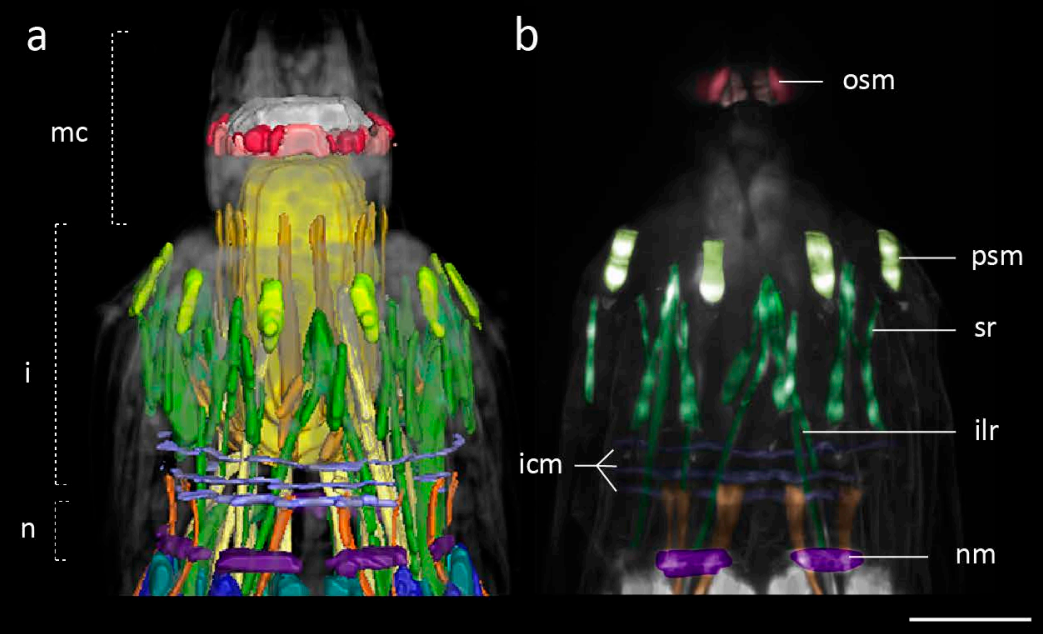

\section{C}

\section{d}

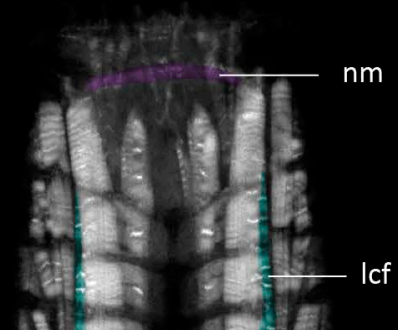

6

7

8

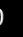
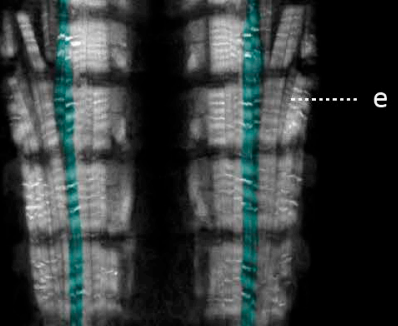

1
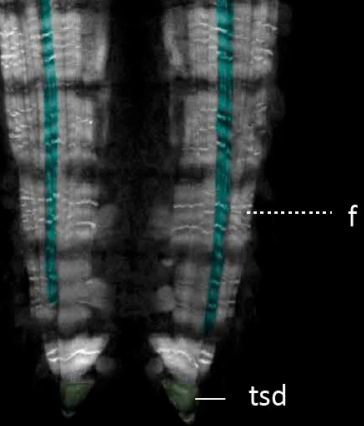

Introvert circular muscles (icm)

- Introvert/spinoscalid retractors (ilr/sr)

- Primary spinoscalid muscles (psm)

- Pharynx bulb (pb)/retractors (pr)

- Pharynx protractors ( $p p)$

Pharynx longitudinal muscles (plm)

Mouth cone circular muscles (mcc)

- Introvert short retractors (isr)

Outer oral style muscles (osm)
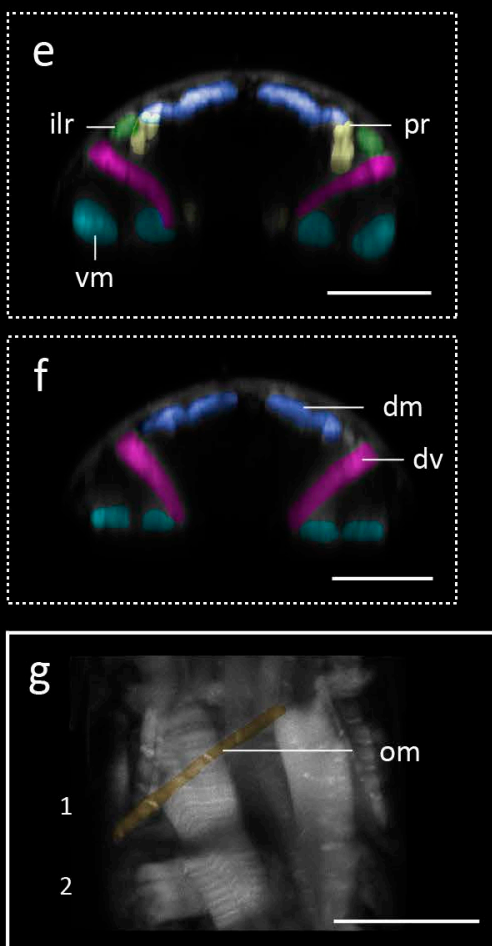

Neck muscles (nm)

- Oblique muscle (om)

- Dorsoventral muscles (dv)

- Ventral muscles (vm)

Dorsal muscles (dm)

- Continuous fibers (Icf)

- Hindgut dilators (hd)

Lateroterminal spine levator (tsl)/ depressor (tsd)

- Tergal muscles (tm) 


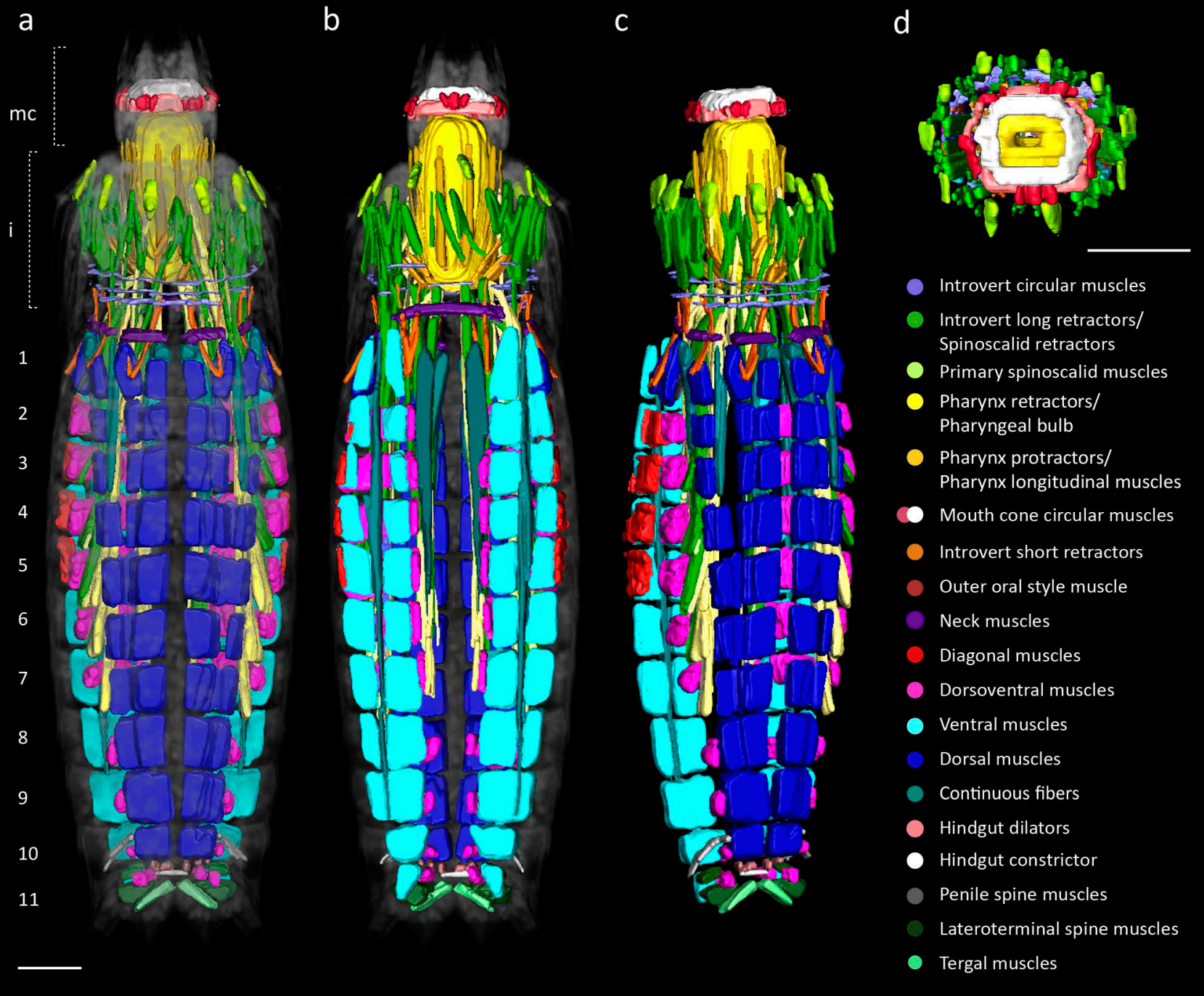




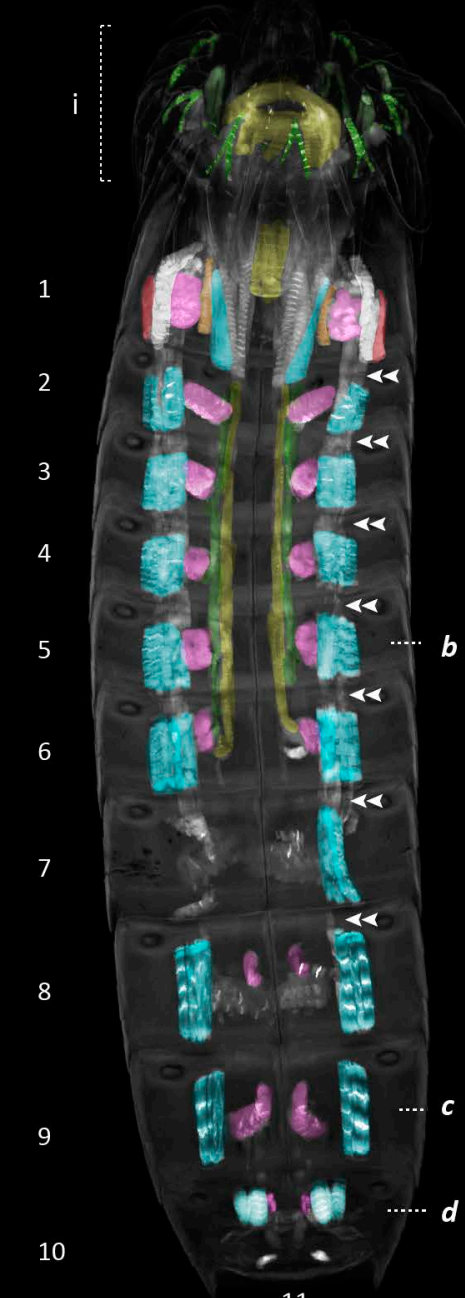

Introvert circular muscles (icm)

- Introvert long retractors/spinoscalid retractors

Oblique muscles (om)

- Pharyngeal bulb/ Pharynx retractors

- Pharynx longitudinal (plm)/transverse muscles

- Introvert short retractors (isr)

- Neck retractors (nr)

Dorsoventral muscles (dv)

- Ventral muscles

Placid transverse muscles (plt)

b

C

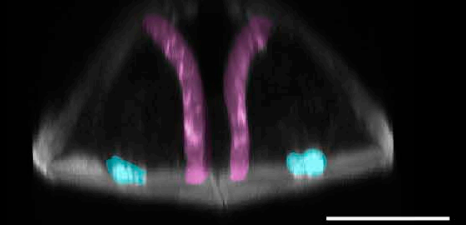

d

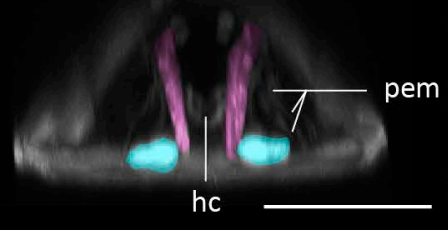

e

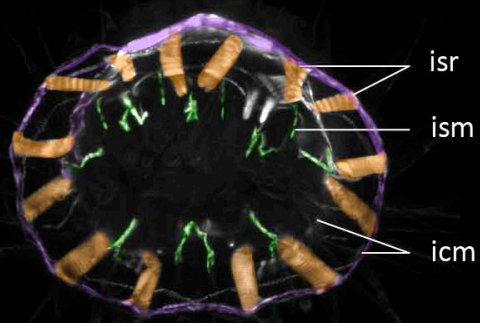

f

$\mathrm{mc}$

1

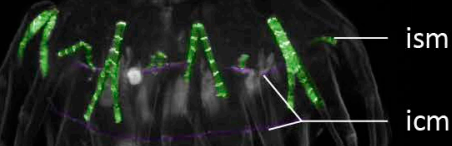

g

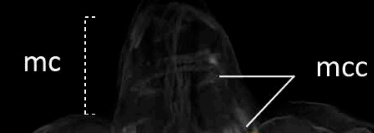

1

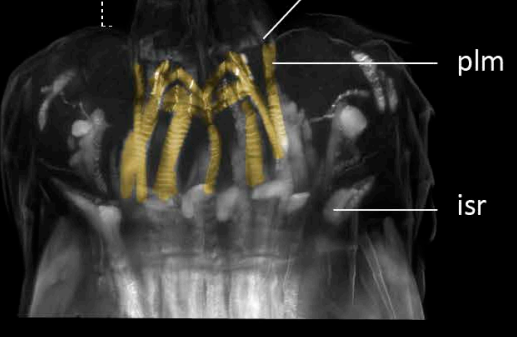

h

1
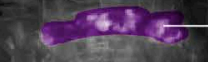

1

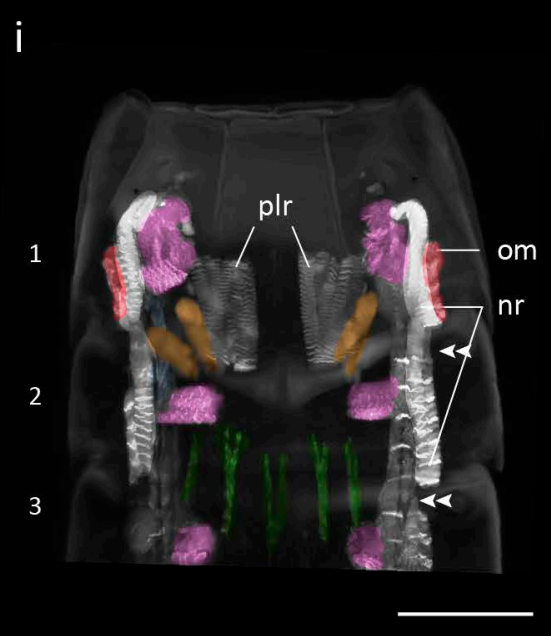

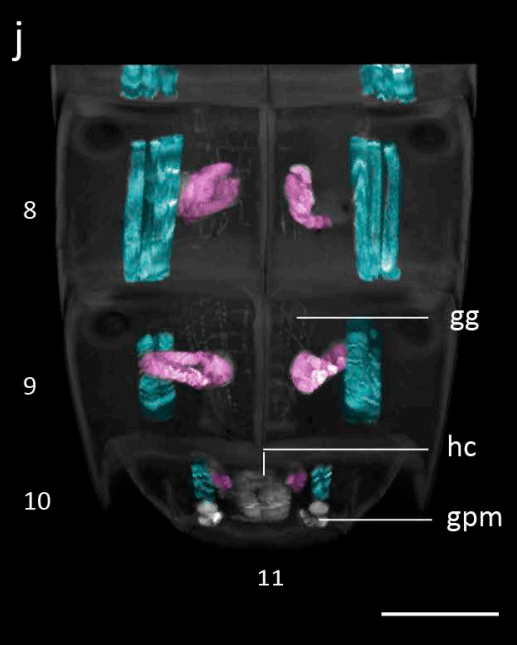


a

b

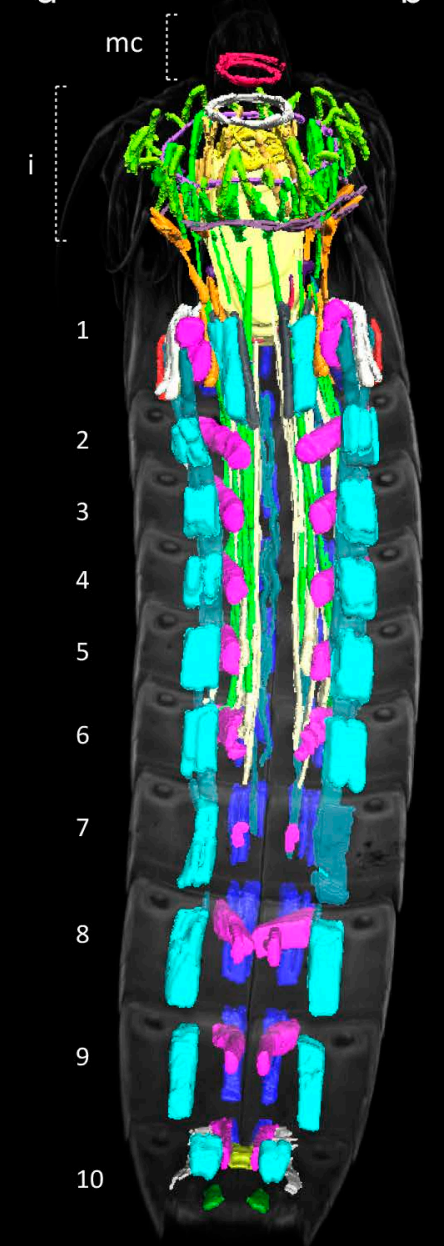

11

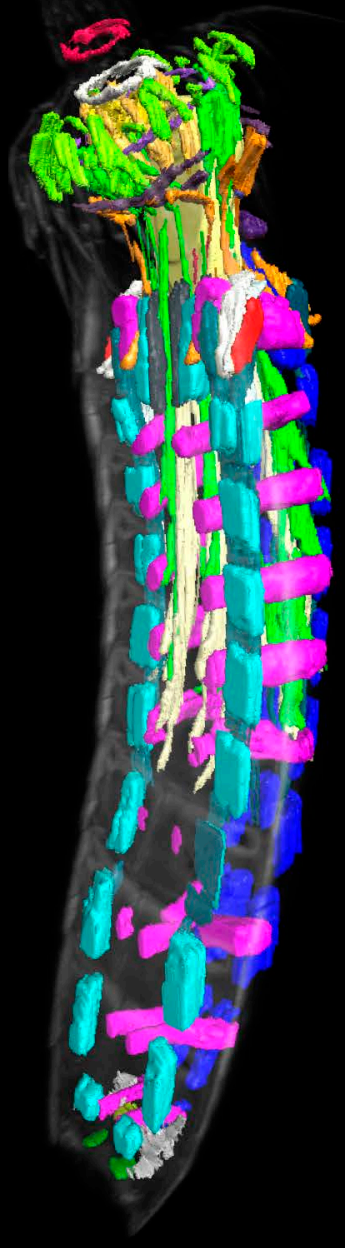

C

d

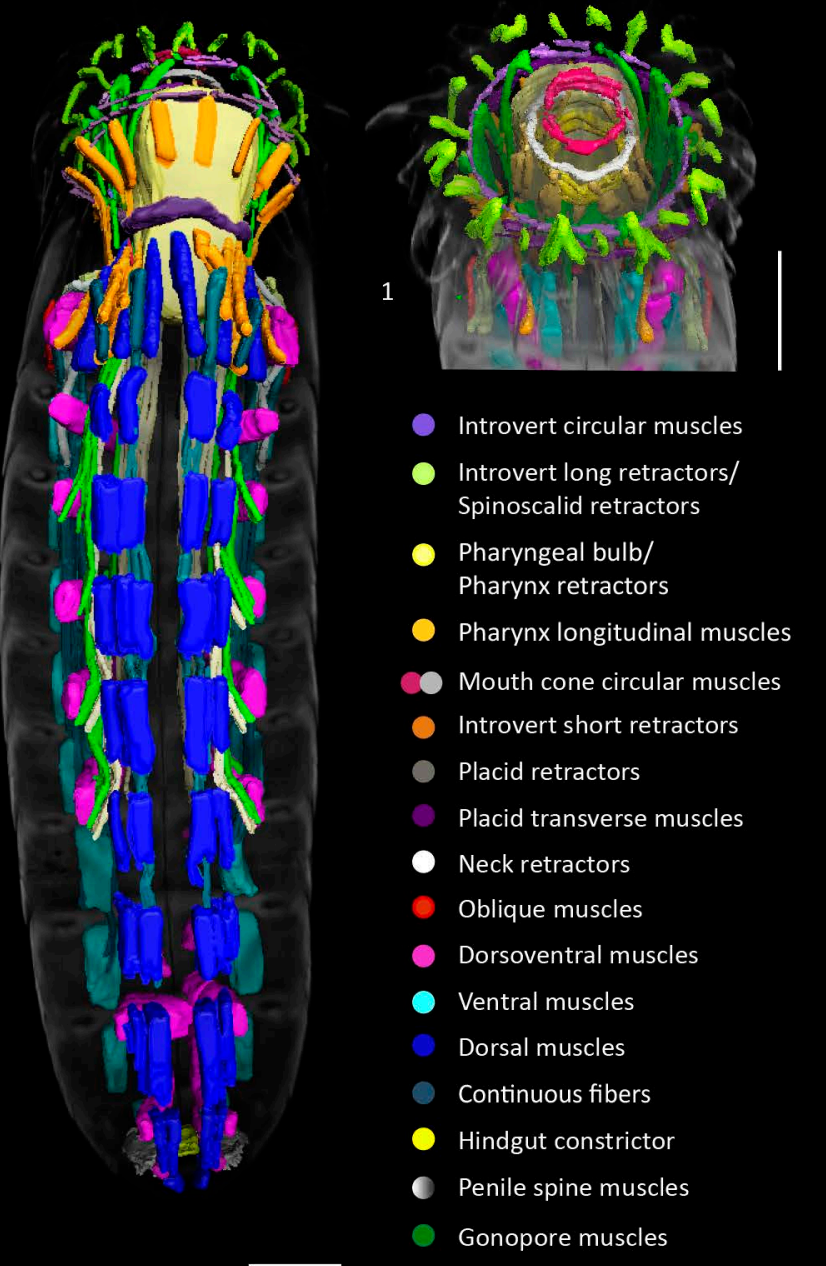




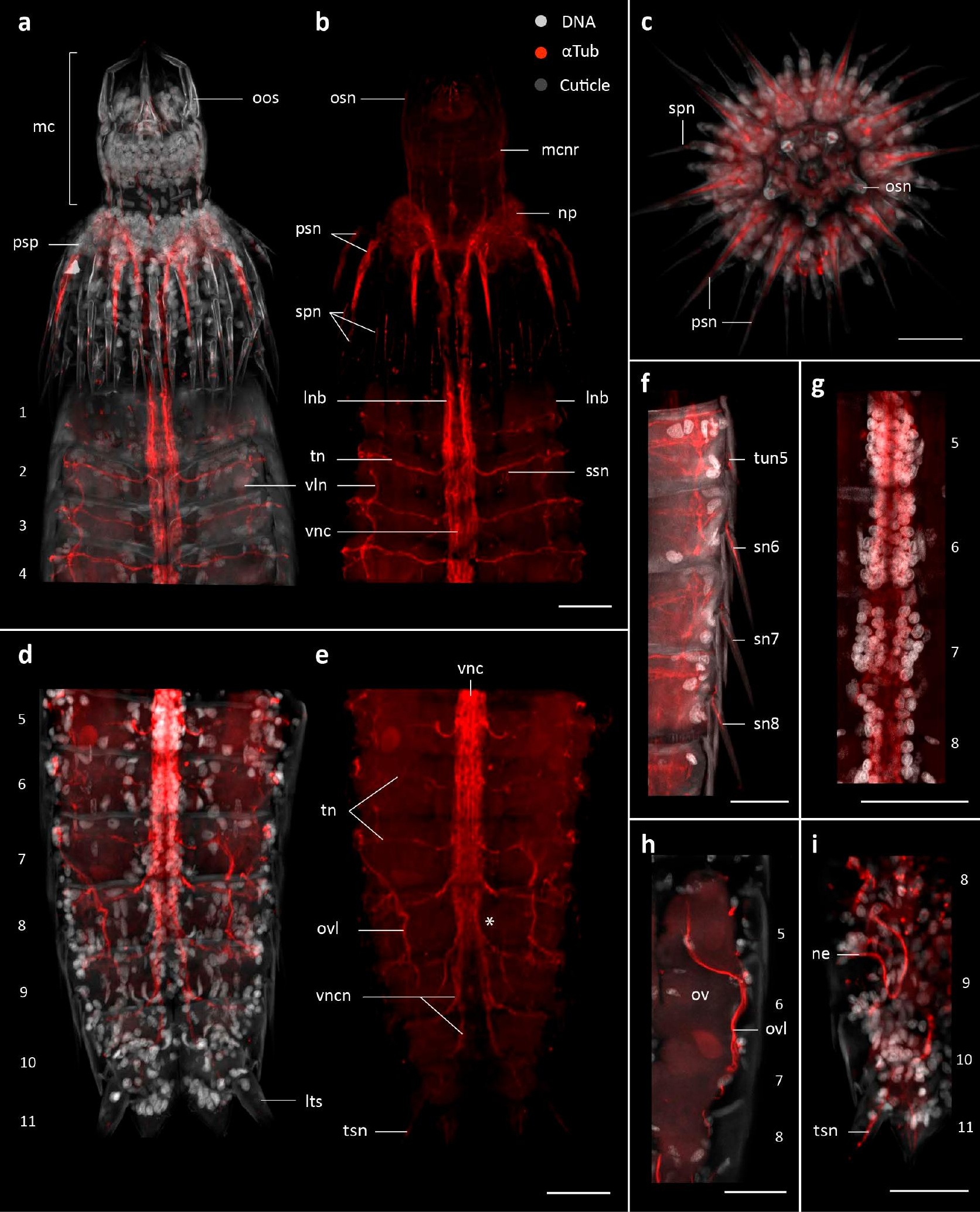




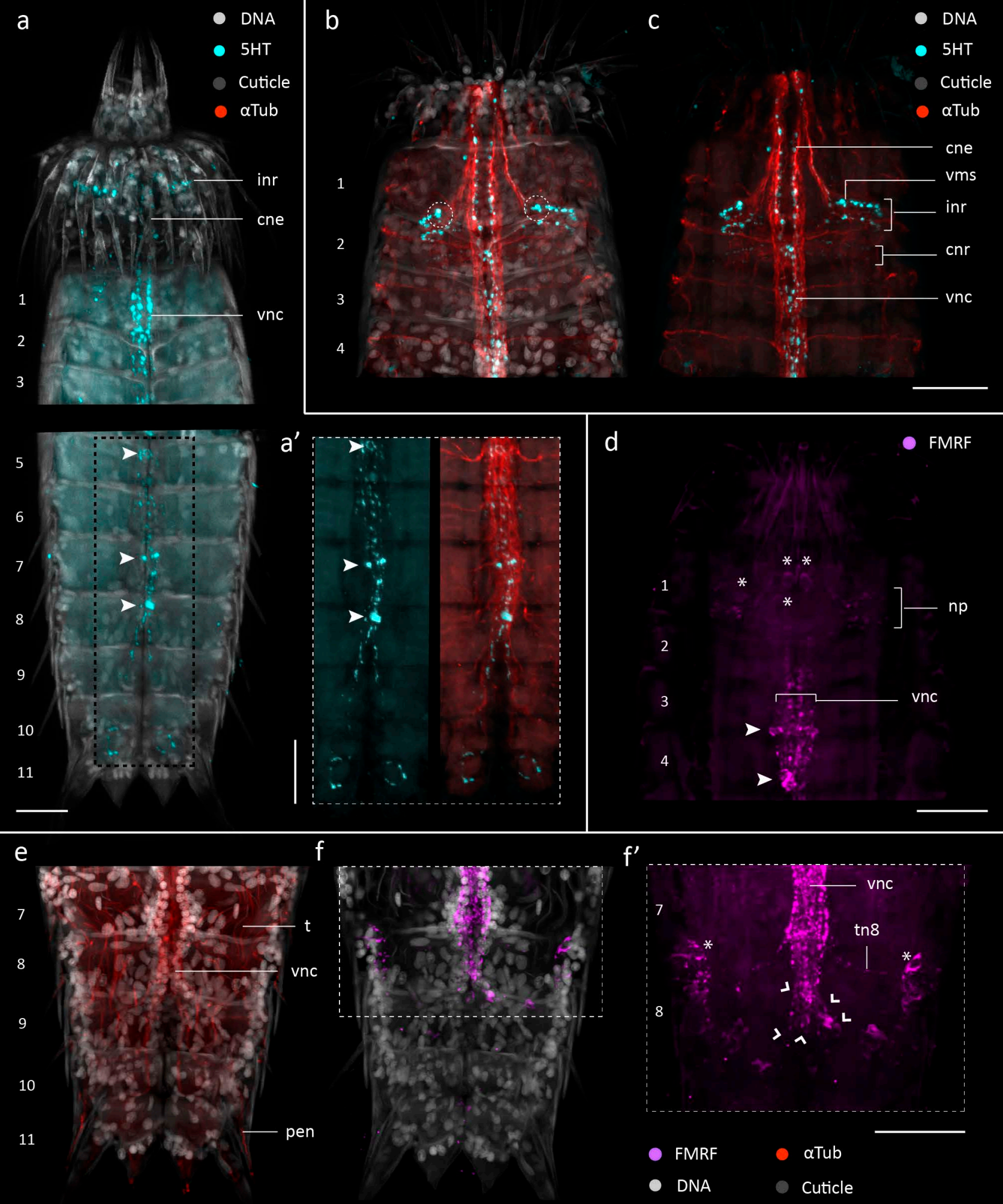




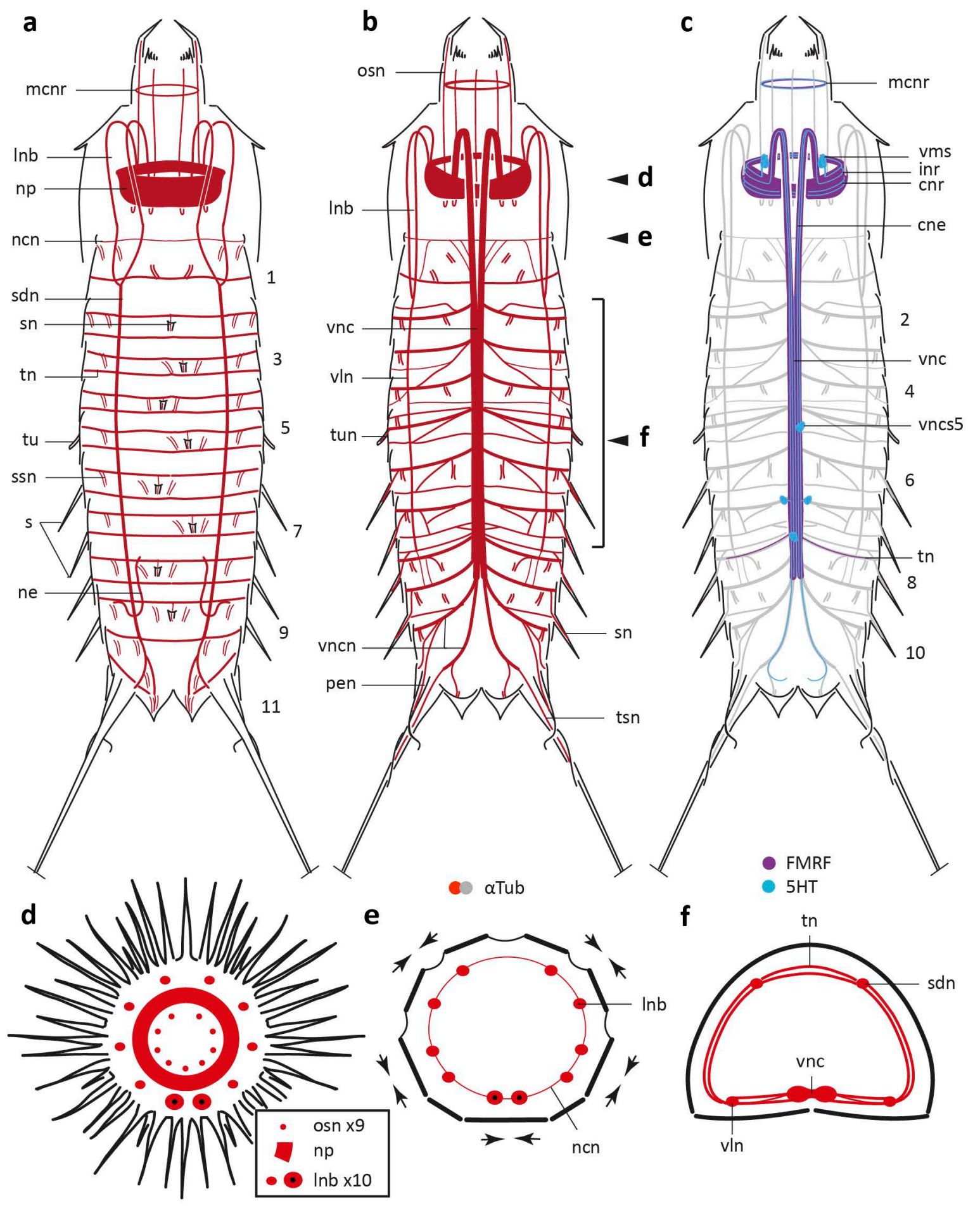




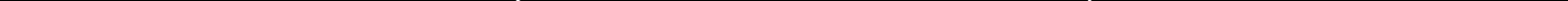


